\title{
4
}

\section{Control of Salmonella in Poultry Through Vaccination and Prophylactic Antibody Treatment}

\author{
Anthony Pavic ${ }^{1,2,4}$, Peter J. Groves 2,3 and Julian M. Cox 4 \\ ${ }^{1}$ Birling Avian Laboratories; \\ ${ }^{2}$ School of Veterinary Science, University of Sydney; \\ ${ }^{3}$ Zootechny; \\ ${ }^{4}$ School of Biotechnology and Biomolecular Sciences, \\ Faculty of Science, University of New South Wales \\ Australia
}

\section{Introduction}

Salmonella are ubiquitous, host-adapted or zoonotic human and animal pathogens and, after Campylobacter, the genus is the second most predominant bacterial cause of foodborne gastroenteritis Worldwide (Giannella, 1996; Smith, 2003). Numerous foods (meat, seafood, eggs, fresh horticulture, table eggs and poultry) have been associated with Salmonella carriage or contamination (FAO/WHO, 2002; Jay et al., 2003; Foley and Lynn, 2008).

Poultry meat has been associated frequently and consistently with the transmission to humans of enteric pathogens, including Salmonella and Campylobacter (Food and Agriculture Organisation of the United Nations and the World Health Organisation [FAO/WHO], 2002; Codex Alimentarius Commission, 2004; EFSA, 2007; Lutful Kabir, 2010; Vanderplas et al., 2010 and Cox and Pavic, 2010). Moreover, Callaway et al. (2008) stated that the "link between human salmonellosis and host animals is most clear in poultry" and that raw eggs and undercooked poultry are considered by the entire community to be hazardous. Eggs have been implicated as vehicles in numerous outbreaks of salmonellosis; in particular, eggs have been a major vehicle of transmission of strains of Salmonella serovar Enteritidis, though the incidence of disease associated with this particular mode of transmission has decreased dramatically (Braden, 2006).

There have been large increases, in Australia and the United States of America (6.5 times), in per capita consumption of poultry products since 1910, compared with modest increases $(20 \%)$ in consumption of beef and pork (Buzby and Farah 2006; ABARE, 2008). Chicken meat is close to replacing beef as Australia's preferred meat, largely because of the industry's success in reducing real (net of inflation) supply costs and hence price to consumers, and through continuous product innovation. The chicken meat industry has reduced supply costs by consistently raising both on-farm and off-farm productivity over several decades through a combination of better management, genetic improvement, economies of scale and mechanisation in processing (ABARE, 2008). 
With projected increases in poultry consumption and the association of Salmonella with poultry products, the industry needs to employ specific and economic strategies to minimise risk to public health. The production of commercial poultry uses a pyramidal multiplier structure, with breeders at the apex and broilers at the base.

The two broad approaches to Salmonella control are 'top down' and 'bottom up', with the latter used widely in Australia. This approach uses spin chiller chlorination within the processing plant for reduction of microbial populations. This method has limited success in reduction of Salmonella prevalence and, with consumer choices moving towards 'natural' (chemical free) products, has lead to experimentation with and application of 'top down' intervention strategies. A 'top down' approach, using vaccination at breeder level, can be very cost-effective and is a proven method of flock protection for both viral and bacterial pathogens such as Infectious Bursal Disease Virus, Inclusion Body Hepatitis and Mycoplasma (Marangon and Busani, 2007).

The increasing costs or impracticality of improvements in biosecurity, hygiene and management, coupled with the increasing problems associated with antibiotic resistance, suggests that vaccination in poultry will become more attractive as an adjunct to existing control measures (Zhang-Barber et al., 1999).

Although Salmonella is typically not a pathogen in the gut of the chicken, systemic infection can cause serious disease (fowl paratyphoid) in the bird (Lutful Kabir, 2010). This usually results from contamination of egg shells from infected breeder hens and spread of the organism into the respiratory tract during hatching which may result in potentially high morbidity and mortality in young chicks (Lutful Kabir, 2010).

Salmonella vaccines available to the poultry industry are based on inactivated or killed cells or genetically attenuated strains (Methner et al., 1999; Babu et al., 2003). However, with concerns in Australia over the use of genetically modified organisms in the food chain, until 2008, only inactivated vaccines were available for use (Anonymous, 1999).

Vaccination against Salmonella was first demonstrated to be successful in decreasing poultry mortality due to the poultry-specific Salmonella serovar Gallinarum (Smith, 1956). This success, and the Enteritidis disaster in table eggs during the late 1980s that occurred in Europe and the United Kingdom, lead to the development of a Salmonella Enteritidis vaccine, which reduced the prevalence of the serovar in poultry. This was followed by a combined (dual) vaccine containing serovars Enteritidis and Typhimurium that again aided in the reduction of carriage in flocks (Clifton-Hadley et al., 2002; Woodward et al., 2002).

Van Den Bosch (2003) reported success with inactivated Salenvac ${ }^{\circledR}$ vaccines in the European poultry industry, which has been associated with a decline in the presence of $S$. Enteritidis and Typhimurium in England. Salenvac ${ }^{\circledR T}$ is a bivalent $S$. Typhimurium and $S$. Enteritidis bacterin-based vaccine, developed from the monovalent Salenvac ${ }^{\circledR} S$. Enteritidis bacterin (Clifton-Hadley et al., 2002).

Based on these studies, production of a trivalent vaccine was initiated in 2004 in association with Intervet Schering-Plough Australia Pty Limited, incorporating the three most predominant Salmonella serovars, Typhimurium (group B), Mbandaka (group C) and Orion (group E), from a commercial poultry meat producer, determined through in-house analysis of environmental samples from breeder houses. 
Australian poultry companies need to ensure that their operations are free of the specific serogroup D serovars that are present in poultry, including the host-specific chicken pathogens, Gallinarum and Pullorum (Barrow et al., 1994) as well as Enteritidis (Arzey, 2005), a serovar of significant public health concern. This is achieved by ongoing monitoring of hatcheries, feed mills and poultry rearing houses, and culling all positive flocks; therefore these serovars are no longer endemic, with only sporadic cases in Australian broiler and layer flocks (Davos, 2007).

On the other hand, Salmonella Typhimurium, which is associated typically with at least 35\% of human cases of salmonellosis in Australia, is present in $14 \%$ of broiler and $17 \%$ of layers isolates (Davos, 2007). Furthermore, other predominant Salmonella serovars isolated from broilers and layers include Sofia (38 \% broiler, $0 \%$ layer), Infantis (10\% broiler, $8.9 \%$ layer), Montevideo (8.8\% broiler, 5.7\% layer), Muenster (7.8\% broiler, $0 \%$ layer) and Mbandaka (<1.7\% broilers, $10.5 \%$ layers), (Davos, 2007).

The vaccinated or naturally challenged hen protects her progeny through maternal antibodies (IgY) transported into the egg yolk (Kowalczyk et al., 1985). These maternal antibodies offer some protection to the hatchling until its own immune system is fully functioning (Kowalczyk et al., 1985). The IgY suspended in egg yolk can be easily extracted via chemical methods, and purified (Ko and Ahn, 2007). Therefore Salmonella vaccinated hens can transfer to the yolk IgY that can be extracted, measured and used prophylactically (in feed) to protect young chicks from initial Salmonella colonisation (Vanderplas et al., 2010; Cox and Pavic, 2010).

The objectives of this research were to develop an autogenous tri-vaccine to prevalent poultry serovars, test whether heterologus protection is possible, and if specific antiSalmonella IgY, extracted from the eggs from vaccinated hens, confers prophylactic protection to day old chicks.

\section{Material and methods}

The methods summarised in this section are divided into three sections, with general, vaccine trial and prophylactic methods individually described.

\subsection{General methods}

The methods summarised in this section describe the common techniques that were used throughout the experimental work. These methods include: the Salmonella strains, challenge suspension and isolation testing; blood and yolk collection and their subsequent testing with the anti-Typhimurium ELISA; trial farm setup and the animal ethics requirements.

\subsubsection{Salmonella strains}

All Salmonella enterica subsp. enterica strains used in this research (Table 1) were from Birling Avian Laboratories Reference Collection, isolated from the field (production environment), and typed by the Institute of Medical and Veterinary Science (IMVS) in accordance with the White-Kauffmann-Le Minor scheme (Grimont and Weill, 2007). 


\begin{tabular}{cccc}
\hline Serogroup & Antigenic structure & Serovar & Abbreviation \\
\hline \hline B & $1,4,[5], 12 \mathrm{f}, \mathrm{g}, \mathrm{s}[1,2][\mathrm{z} 27],[\mathrm{z} 45]$ & Agona & SA1 \\
B & $1,4,[5], 12 \mathrm{i} 1,2$ & Typhimurium & ST12 \\
C & $6,7, \underline{14}, \mathrm{r} 1,5[\mathrm{R} 1 .],.\left[\mathrm{z}_{37}\right],\left[\mathrm{z}_{45}\right],\left[\mathrm{z}_{49}\right]$ & Infantis & SI1 \\
C & $6,7,14 \mathrm{z} 10 \mathrm{e}, \mathrm{n}, \mathrm{z} 15[\mathrm{zz} 37],[\mathrm{z} 45]$ & Mbandaka & SM1 \\
E & $3,\{\underline{10}\},\{\underline{15,34}\}, \mathrm{y} 1,5$ & Orion & SO1 \\
E & $3,\{10\}\{15\} \mathrm{k} 1,5$ & Zanzibar & SZ1 \\
\hline
\end{tabular}

Table 1. Salmonella challenge strains belonging to serogroups B, C and E with their respective abbreviation used in the text.

Pure cultures on nutrient agar (NA, Oxoid Thermo Fisher, CM3) were harvested with a cotton swab (Copan, Ref 8155CIS, Italy.) and preserved (10 per serovar) in Cryovials (PROLAB Diagnostic, REFPL.170/M, Ontario, Canada) stored at $-70^{\circ} \mathrm{C}$.

\subsubsection{Salmonella suspension for challenge}

For each Salmonella strain, a bead from a Cryovial (PRO-LAB Diagnostic, REFPL.170/M, Ontario, Canada) was incubated in $100 \mathrm{~mL}$ of buffered peptone water (BPW, Oxoid Thermo Fisher, CM509, Hampshire, UK) to produce a seed culture. Purity of the culture was checked on NA and identity confirmed serologically using antisera (PRO-LAB Diagnostic Ontario, Canada; Refs TL6002 [O], TKL6001 [H], RL6011-04 [B], PL6013 [C] and PL6017 [E]).

After purity was confirmed and serology determined, isolated colonies were selected and suspended in BPW $(4 \mathrm{~mL})$ to give a $75 \%$ transmittance $\left(1.0 \mathrm{McF}\right.$ arland) equating to $2 \times 10^{8}$ cfu / mL (bioMérieux, 47100-00 DR 100 Colorimeter, Marcy l'Etoile, France). The target dosage required was achieved through decimal dilution, with the target dilution used as inocula in challenge or recovery experiments, in accordance with AS/NZS5013.11.1 (2004) and confirmed by spread plate enumeration on $\mathrm{SM}^{\circledR} \mathrm{ID}_{2}$ (bioMérieux, Ref 43621, Marcy l'Etoile, France).

\subsubsection{Salmonella isolation, confirmation and serological testing}

All testing was performed at a laboratory accredited by the National Association of Testing Authorities (Australia) in accordance with ISO 6579:2002. The Salmonella serovars, listed in Section 2.1.1, were isolated from commercial poultry houses (from visceral emulsions, drag swabs and faeces) on the Eastern seaboard of Australia.

Samples were initially emulsified 1:10 in BPW and incubated at $37^{\circ} \mathrm{C}$ for $24 \mathrm{~h}$ (standard incubation temperature unless otherwise stated). Aliquots of $1000 \mu \mathrm{L}$ and $100 \mu \mathrm{L}$ were transferred into selective Muller Kauffman (MK, bioMérieux, Ref 42114, Marcy l'Etoile, France) and Rappaport-Vassiliadis (RV, bioMérieux, Ref 42110) (incubated at $42{ }^{\circ} \mathrm{C}$ for $24 \mathrm{~h}$ ) broths respectively.

The following validated modifications to ISO 6579:2002 were used. The selective-differential plating agars were Hektoen and XLD (Oxoid Thermo Fisher, PP2027, Adelaide, Australia) and suspect positives (black colonies with clear edges) were confirmed on chromogenic $\mathrm{SM}^{\circledR} \mathrm{ID}_{2}$ instead of the standard biochemical tests (urease, sorbitol fermentation and iron agar reactions). 
Presumptive Salmonella were serologically confirmed with poly-O and poly-H antisera (ProLabs Diagnostic, Refs TL6002 and TKL6001, Ontario, Canada) after subculture onto two slopes of NA and employing the slide agglutination technique. The confirmed Salmonella isolates (each on a NA slope) were forwarded to the Australian Salmonella Reference Laboratory at the Insitute of Medical and Veterinary Science (IMVS) for complete serological and phage typing.

\subsubsection{Blood collection}

Blood was collected using a 21-gauge needle (Greiner bio-one, 450072, Germany.) into a 2 $\mathrm{mL}$ serum collection tube (Vacuette, 454096, Greiner bio-one, Austria) and, after clotting, transported to the laboratory in chilled containers. The serum was decanted into $1200 \mu \mathrm{L}$ plasma tubes (Scientific Specialist, 1750-00, CA., USA) and the presence of antibodies to the vaccine was determined using a commercially available Salmonella Typhimurium ELISA kit (Guildhay, \{trading as x-OVO since 2008, Castle Court, UK\}, Flockscreen ${ }^{\mathrm{TM}}$, Cat. No V02043308), according to the manufacturer's instructions (2.1.7).

Initially, the serum was diluted (1:500) by adding $5 \mu \mathrm{L}$ of serum into $2.5 \mathrm{~mL}$ reconstituted sample diluent (2.1.7) in plastic $5 \mathrm{~mL}$ tubes (Techno-Plas, 10255001, SA, Aust) and inverted a total of three times to mix.

\subsubsection{Egg yolk collection}

Eggs were collected after laying by mature hens and transported whole to the lab where they were broken and the yolk separated from the white using a domestic egg separator. The yolk was then poured into a $70 \mathrm{~mL}$ sterile jar (Techno-Plas, 10431011, SA, Aust) from which a $200 \mu \mathrm{L}$ aliquot was removed and added to $1.8 \mathrm{~mL}$ of reconstituted wash buffer and mixed by repeated $(5 \mathrm{x})$ aspiration. The yolk was further diluted (1:50) by pipetting $50 \mu \mathrm{L}$ into $2.5 \mathrm{~mL}$ of reconstituted sample diluent buffer (2.1.7).

\subsubsection{Immunoglobulin $Y$ extraction}

Only Typhimurium ELISA-positive or suspect (2.1.7) egg yolks from Section 2.1.5 were used for IgY extraction. The method selected was the water dilution method described by Staak $e t$ al. (2001). Initially, the weighed ELISA positive egg yolks were diluted 1:5 w/v with distilled water, mixed vigorously by vortexing (15 s) and frozen at $-20^{\circ} \mathrm{C}$ for $72 \mathrm{~h}$. Postfreezing the yolk suspension was thawed slowly in a refrigerator at $4{ }^{\circ} \mathrm{C}$.

The thawed yolk water suspension was transferred into centrifuge tubes $(50 \mathrm{~mL})\left(\right.$ Greiner ${ }^{\circledR}$, T2318, Sigma-Aldrich, St Louis, MO, USA) and centrifuged (Eppendorf, 5810R, Hamburg, Germany) at 2,800 $\times g$ (Equation 1) for 20 minutes at room temperature.

$$
\begin{gathered}
\mathrm{RCF}=1.118 \times 10^{-5} r \mathrm{~N}^{2} \\
g=r(2 \Pi \mathrm{N})^{2} / \mathrm{RCF} \\
\mathrm{RCF}=\text { Relative centrifugal force. } \\
r=\text { rotation radius in centimetres. } \\
\mathrm{N}=\text { revolution per minute } \\
g=\text { gravitational force } \\
\Pi=P i
\end{gathered}
$$

Equation 1. Calculation of centrifugal $g$ forces. 
Post-centrifugation, the supernatant was decanted into a volumetric cylinder and the precipitate discarded. To each millilitre of supernatant, $0.27 \mathrm{~g}$ of ammonium sulphate ('salt') was added, mixed by vortexing (15 s) and incubated at room temperature for $2 \mathrm{~h}$. Postincubation the 'salt'-yolk suspension was centrifuged as mentioned previously and the supernatant was discarded.

The precipitate containing IgY was resuspended, in $24 \mathrm{~mL}$ of ammonium sulphate $(2 \mathrm{M})$, vortexed (15 s) and incubated at room temperature for $40 \mathrm{~min}$. After incubation, the saltyolk suspension was re-centrifuged and the supernatant discarded. The final precipitate of crude IgY was resuspended (vortex $15 \mathrm{~s}$ ) in $5 \mathrm{~mL}$ of phosphate buffered saline, transferred to a $10 \mathrm{~mL}$ sealable test tube (Techno-Plas, 10281003, SA, Aust.) and stored at $4{ }^{\circ} \mathrm{C}$.

\subsubsection{Typhimurium ELISA method}

The ELISA was performed in accordance with the manufacturer's instructions (Guildhay, Castle Court, UK). Briefly, kits were allowed to reach room temperature and the wash buffer (100 mL \{phosphate buffer with ProClin $0.63 \% \mathrm{v} / \mathrm{v}$ \} to $1900 \mathrm{~mL}$ deionised water) and sample diluent $(100 \mathrm{~mL}$ \{phosphate buffer with protein stabiliser and ProClin $0.63 \% \mathrm{v} / \mathrm{v}$ \} to $900 \mathrm{~mL}$ deionised water) prepared.

Into individually pre-coated (Typhimurium somatic liposaccaride antigen) ELISA strips containing eight wells, $50 \mu \mathrm{L}$ was dispensed of positive controls $(\mathrm{x} 2)$, followed by negative controls (x2) and finally the test sample(s). The ELISA plate(s) were covered with an adhesive plastic film (Sealplate, 100-seal-PLT, Excel Scientific Inc, Victorville, CA, USA), mixed by gently tapping the side and then incubated at $37^{\circ} \mathrm{C}$ for $30 \mathrm{~min}$.

Post-incubation, after removal of the adhesive cover, each well was washed four times (100 $\mu \mathrm{L}$ per well/per wash cycle) in a pre-programmed ELISA Plate washer (Immunowash, 1575, BioRad, CA, USA) with the reconstituted wash buffer. After washing, the plates were dried (five firm taps) by inverting them over paper towel. Once dry, $50 \mu \mathrm{L}$ of antibody-enzyme conjugate (donkey anti-chicken IgG \{Guildhay, Castle Court, UK\}) was pipetted into each well. The plate was resealed, mixed and incubated as described previously.

Following incubation, the wells were washed as above, then $50 \mu \mathrm{L}$ of ELISA substrate reagent (alkaline phenolphthalein monophosphate and enzyme co-factors in a diethanolamine buffer) were added, and the plates covered, mixed and incubated at $37{ }^{\circ} \mathrm{C}$ for $15 \mathrm{~min}$. The final step was to add $50 \mu \mathrm{L}$ of ELISA stop solution (1 M sodium hydroxide), ensuring that any bubbles formed were removed, then the plates were analysed in a blanked Microtitre Plate Reader (Vmax Kinetic microplate reader, Molecular Devices, CA, USA) at $\lambda 550 \mathrm{~nm}$.

The Guildhay ELISA can detect anti-Typhimurium antibodies, within serum or egg yolk, at an initial dilution of 1:500. After the optical density (OD) all wells was measured at $\lambda 550 \mathrm{~nm}$, the sample OD was compared to the mean positive controls OD (Equation 2) to produce the Sample / Positive (S/P) ratio. Using Equation 3 the S/P ratio was converted into a titre.

Sample Optical Density - mean Negative Optical Density

Mean of Positive Optical Density - mean Negative Optical Density

Equation 2. Sample to Positive ratio calculation. 


$$
\begin{gathered}
\log _{10} \text { titre }=1.046 \times\left(\log _{10} \mathrm{~S} / \mathrm{P}\right)+3.524 \\
\text { Titre }=\text { antilog of } \log _{10} \text { titre }
\end{gathered}
$$

Equation 3. Salmonella Typhimurium titre calculation from S/P ratio.

The Typhimurium titres were initially calculated manually, though software (Guildhay, Castle Court, UK) is available that performs all the calculations and reports the values as $\mathrm{OD}, \mathrm{SP}$ or titres. According to the kit manufacturer (Guildhay) the lowest threshold for a positive was an SP ratio $>0.25$ (titre $>785$, OD $>0.173$ ), negative $\mathrm{SP}<0.15$ (titre $<459$, $\mathrm{OD}<$ 0.15 ) and a suspect band SP 0.15 to 0.25 (titre 460 to 784 , OD 0.15 to 0.173 ).

\subsubsection{Trial farm set up}

The trial house used was an insulated broiler house with side curtains for ventilation control, equipped with two gas-fired space heaters for brooding, and internal fans and roof sprinklers for cooling. The house was divided into 32 individually numbered floor pens, 2.5 x $3 \mathrm{~m}$, with individual bell drinkers and two tube feeders.

To minimise cross-contamination and identify the presence of non-inoculant Salmonella the following procedure was used in all trials. Prior to the trial all pens were disinfected using a synthetic phenol (Farm Fluid ${ }^{\mathrm{TM}}$, Antec International, Suffolk, UK), drag-swabbed and tested for the presence of Salmonella. Fresh litter (wood shavings) was spread evenly across each pen and drag-swabbed again. A footbath, containing a commercially available iodophorbased sanitizer (Sanichick ${ }^{\mathrm{TM}}$, Ranvet, Sydney, Australia), was placed outside each of the pens. An empty pen was left between all populated pens, with controls located furthest from the entrance; all routine maintenance started from the controls and worked backwards. Vermin baits, pest strips and an Insectocuter were placed around the house.

The pens were divided into treatment sets, i.e. vaccination, (north side of house) and control, i.e. non-vaccinated (south side of house), with feed and water supplied ad libitum. Disposable overalls (Fabri-cell, 05250XL, Vic. Aust.), dust masks (3M, 9320, UK) and gloves (Livingstone Int, GLVLPF100LG-T, NSW, Aust.) were worn inside the house at all times and changed between treatment and control groups. Biohazard bags (Bacto, BCWB66112, Sydney, Aust.) were used to remove contaminated waste, litter and to transport culled or naturally deceased chickens. Hands were washed with an iodophor-based disinfectant, prior to leaving the house. Post-trial the house was disinfected with phenolic-based chemicals and drag-swabbed.

At the termination date, the chickens were euthanized by lethal intraperitoneal injection with $0.5 \mathrm{~mL} / \mathrm{kg}$ pentobarbitone (Lethabarb®, Virbac Pty Ltd, 1PO643-1, Carros Cedex, France). The carcasses were transported in biohazard bags back to the laboratory and the caeca were removed aseptically by a veterinarian, cut into ten pieces and placed into a single sterile $250 \mathrm{~mL}$ sample jar (Techno-Plas, 10453003, SA, Aust.), diluted as per specific procedure with BPW, then incubated for detection as described in Section 2.1.3.

\subsubsection{Animal ethics}

The Birling Animal Ethics Committee (BAEC), supervised all experimental work in accordance with the Animal Research Act of NSW (1985) and Regulations (2005), following the NHMRC (National Health and Medical Research Council) guidelines (2008) and 
NHMRC/ARC (National Health and Medical Research Council, Australian Research Council and Universities Australia) Code of Conduct (2007). When the project was approved, it was designated with a unique BAEC number and a time period for completion.

\subsection{Vaccine trial}

This section describes the process from the original controlled animal pen to field trials, which occurred over a period of three years.

\subsubsection{Vaccine manufacture and administration}

Intervet Schering-Plough Australia was commissioned to produce an autologous trivalent inactivated vaccine using proprietary Salenvac ${ }^{\circledR}$ technology from poultry field isolates of Typhimurium, Mbandaka and Orion. Strains were grown on iron-depleted agar, improving specifically the expression of the antigenic iron regulatory proteins (IRPs), further stimulating the humoral response and increasing antibody titres (Van Den Bosch, 2003). The trivalent vaccine was produced using equal amounts of cell suspension $\left(3 \times 10^{8} \mathrm{cfu} / \mathrm{mL}\right)$, combined with an aluminium hydroxide adjuvant, and administered to hens intramuscularly into the breast, at 12 and 17 weeks of age.

\subsubsection{Experimental animals}

In Experiment 1 a total of 50 vaccinated and 50 non-vaccinated, 20-week-old Cobb breeders were placed into trial pens at a minimum of 12 per group, with the remainder used as negative controls. These were obtained from a commercial broiler breeder farm where the vaccine regimes were administered under commercial conditions. All birds where individually labelled with leg or wing tags and blood and rectal swabs collected and tested five days prior to challenge.

In Experiment 2 a total of 100 non-vaccinated, 12 week old Cobb breeders were placed into the trial pens (12 per group) as mentioned previously. In Experiment 3 Cobb broiler day old chicks $(n=100)$ were sourced from a commercial hatchery from vaccinated $(n=50)$ and nonvaccinated parents $(n=50)$.

\subsubsection{Adult hen challenge design and trial (experiment 1 and 2)}

The number of birds required for each experiment was calculated using statistical tables as described by Martin et al., (1988) to determine the lowest number of repeats required to demonstrate a difference of $20 \%$ prevalence between vaccinated (expected $30 \%$ prevalence) and non-vaccinated (expected $50 \%$ prevalence) groups, at $90 \%$ confidence.

As this study involved a new vaccine, the standard deviation of titres following vaccination was unknown. Therefore, 12 birds per group allowed estimation of the average result within a bound of $0.5 \mathrm{x}$ standard deviation from a flock of $>300$ birds, at $90 \%$ confidence (Hancock et al., 1988).

Each trial required the use of only half the trial house (2.1.8) and therefore the other half was sectioned off. The controls were placed furthermost away from the entrance to minimise any cross-contamination. The challenge groups were placed in pens that were opposite each 
other. Each bird was challenged with $250 \mu \mathrm{l}$ of the $10^{7} \mathrm{cfu}$ Salmonella suspension via oral gavage using a $2 \mathrm{~mL}$ variable volume pipette (Finnpipette stepper, 4540000, Thermo Electron Corp. Waltham, MA, USA).

The initial experiment (Experiment 1) involved autologous challenge (i.e. with the parent vaccine strains) and the subsequent experiment (Experiment 2) involved heterologous challenge, using alternative, poultry-associated serovars from the same respective serogroups as the vaccine strains: Agona (SA1, serogroup B); Infantis (SI1, serogroup C), and; Zanzibar (SZ1, serogroup E). An additional group, challenged with Typhimurium, was used to show repeatability. Cloacal swabs were taken at days 0,3 and 14 post-challenge. At day 21 post-challenge each bird was bled, humanely euthanized and their caeca removed for culture.

Prior to the heterologous (Experiment 2) trial, the hens were sourced as 10-week old birds, prior to vaccination (12 weeks of age), from a commercial broiler breeder farm that was Salmonella-free (confirmed by testing of drag swabs and faeces). These hens were individually tagged and bled, then hand-vaccinated via intra-muscular injection and bled again at 14, 16, 18 and 20 weeks of age.

\subsubsection{Progeny challenge trial (experiment 3)}

In this trial, 100 chicks were obtained from a commercial hatchery, from eggs produced by vaccinated $(n=50)$ and non-vaccinated birds $(n=50)$. The chicks were vaccinated according to current broiler practices (Marek's Disease, Infectious Bronchitis and Newcastle Disease). Chicks were identified as to their dams' vaccination status by toe web marking and were placed in the trial house at 10 chicks per pen. Pen dividers were used to keep birds close to feed and water, with 2 pens of chicks for each progeny group and challenge (total of 10 pens).

At arrival, blood samples were collected from 12 euthanized (cervical dislocation) chicks of vaccinated and non-vaccinated groups, for $S$. Typhimurium antibody assay (2.1.7). The paper from each box of chicks delivered to the farm was cultured for Salmonella as described in Section 2.1.3. The remaining chicks were challenged with $S$. Typhimurium ST12, $10^{4}$ or $10^{8}$ cfu per bird by oral gavage, with controls receiving the diluent buffered peptone water

On days 0,3 and 14, cloacal swabs were collected, from a random sample of five birds per pen, for individual Salmonella culture, with blood samples collected via wing bleeding, on days 7, 10 and 14. On day 21 all birds were bled prior to being euthanized by lethal injection (Lethabarb) and their caeca removed for Salmonella testing. All birds were weighed on days 7, 14 and 21 .

Any bird that appeared sick, as described in the bird health monitoring sheet, was euthanized immediately, weighed, necropsied and the caeca cultured for Salmonella (2.1.3).

\subsubsection{Serology}

Blood was collected, using a 20-gauge needle, into a serum collection tube and, after clotting, transported to the laboratory in containers chilled with ice bricks. The presence of antibodies to the vaccine was determined using a commercially available Salmonella Typhimurium ELISA kit, according to the manufacturer's instructions (2.1.7). 
An additional commercial antigen-based ELISA (Idexx, Art.Nr. 99-44100, Liebefeld-Bern, Switzerland), for determination of titres against Salmonella serovars prevalent in swine (Typhimurium, Infantis and Enteritidis), was sourced and used according to manufacturer's instructions, with the following modification. All serum dilutions were 1:500, the previously mentioned $\mathrm{x}-\mathrm{OVO}$ Guildhay conjugate, substrate and stop solution were used, and the ELISA plates read at 550nM.

\subsubsection{Longitudinal analysis}

The prevalence of serovars over time was determined by performing drag swabs on all broiler breeder flocks from two Australian poultry companies, in three states (New South Wales, Victoria and South Australia), which implemented the Salmonella tri-vaccine protocol described in 2.2.2. Swabs were taken at 6, 14, 18, 22, 33, 43 and 53 weeks of age. The Salmonella prevalence data were calculated for the years 2003 (pre vaccination), 2004 (during vaccination) and 2005 (post vaccination).

These data (2003 to 2005) were analysed initially for annual prevalence (total positives / total samples received) and the monthly prevalence was calculated by dividing the monthly positive by total tested. This same data set was used to calculate the age based prevalence and determine the serovars present.

The flocks mentioned previously were also bled (2.1.4) regularly (22, 32, 42 and 52 weeks of age) and the serum $(n=12)$ was tested for anti-Typhimurium antibodies using ELISA (2.1.7). From these data the flock immunity, the number of positive sera from the total tested $(n=$ $12)$, and the flock mean was calculated. The flock serum data were sorted by flock age (weeks) and descriptive statistics (mean, medium, standard deviation and 95\% confidence limits) were calculated.

The final analysis was to compare the effects of vaccination upon Typhimurium colonised chicks (<12 weeks of age). This analysis was performed by reviewing flock data (Typhimurium antibodies titre and corresponding drag swabs) that contain Typhimurium colonised birds, based on the whole of life cycle throughout 2004/2005. These colonised flocks were sorted upon age (weeks) with the corresponding serology and drag swab data added. A flock was deemed negative for Typhimurium if it had two consecutive negative results (i.e. 18 woa positive, 22 woa negative, 33 woa negative then the flock was deemed negative at 22 woa) and that initial age was plotted against the flock mean Typhimurium titre. These data were also used to evaluate if there was a statistical $\left(\chi^{2}\right)$ relationship between high $(>1000)$ and low $(<1000)$ mean antibody titre and flock Typhimurium status at point of lay (25 woa).

\subsubsection{Statistical analysis}

Qualitative data were converted to numerical data, by assigning (0) for non-detection and (1) for detection, and analysed in a $2 \times 2$ contingency table, as described by Petrie and Watson (1999). Statistical significance $(P \leq 0.05)$ was determined using either the Fisher exact test (any cell with $\leq 5$ observations) or the Chi squared test (all cells had $>5$ observations).

The Mantel-Haenszel stratified contingency table test was employed to compare similar treatments stratified across experiments (Thrusfield, 2005). The Student $t$-test was used to 
evaluate the null hypothesis on vaccination status based on anti-Salmonella antibody levels among paired groups of hens. A difference was considered significant at $P \leq 0.05$. All analyses were performed using Statistica ${ }^{\mathrm{TM}}$ (StatSoft Inc, 2001, Tulsa, OK, USA).

\subsection{Immunoprohylaxis trial}

\subsubsection{Dried egg yolk preparation}

Non-fertile eggs were sourced from a commercial poultry company that routinely administers the trivaccine (2.2.1) to their flocks. The eggs $(n=400)$ from three different farms were sourced from young hens with high $(>1000)$ anti-Typhimurium serum antibody titres. Upon arrival at the laboratory, 20 eggs were tested for the presence of yolk antibodies to Salmonella using the Salmonella Typhimurium ELISA kit (2.1.5 and 2.1.7). The remaining egg yolks were pooled into approximately $100 \mathrm{~g}$ lots and homogenised by vortexing for 15 seconds. These pooled eggs were then frozen and freeze dried (Avanti JE, Beckman Coulter, Bree, CA. USA).

The dried egg yolk lots were resuspended (weight/volume) in PBS buffer (2.1.5) and tested for the presence of anti-Salmonella Typhimurium antibodies using ELISA (2.1.7). The lots were composited into one container and homogenised by vigorous shaking and tested $(n=$ 20) for anti-Salmonella antibody, as previously described (2.1.7). The dried egg yolk powder was then stored in an air-tight container until required.

\subsubsection{Crude extraction of $\lg Y$}

The freeze-thaw technique (Staak et al., 2001) with ammonium salt precipitation, described fully in Section 2.1.6, was used.

\subsubsection{Provision in feed}

The feed was divided into three lots: the first lot incorporated 3\% w/w IgY egg yolk (dTIgY) as described by Gurtler et al. (2004). Dried egg yolk powder was mixed through a standard commercial broiler breeder starter ration supplied by a local mill. The second lot included dT-IgY re-composited in water $(\mathrm{w}: \mathrm{v})$ and, in the final lot, the dT-IgY was recomposited $(\mathrm{w}: \mathrm{v})$ in crude IgY extract.

The dosage of dT-IgY was calculated at $3 \%$ of total daily feed intake $(1.42 \mathrm{~g} / \mathrm{chick})$ from the trial mid-point age (11 days of age) according to breeder specifications (Anonymous, 2007). All the feeds were prepared in $250 \mathrm{~mL}$ containers and fed to the chicks. The re-composited dT-IgY was initially smeared onto the beaks of individual chicks and the remainder spread in a straight line on chick paper, prior to supplying the standard ration.

The residual from each of the lots (in $250 \mathrm{~mL}$ containers) was weighed and an initial dilution $(1: 10)$ was made with Salmonella Typhimurium ELISA buffer. This suspension was diluted (1:2) in plasma tubes and Typhimurium IgY was tested using the ELISA method (2.1.7). The endpoint titre was converted to titre per gram of feed.

\subsubsection{Challenge strain}

A cryobead of Salmonella Typhimurium (ST12), isolated and prepared as in Section 2.1.2, was used as the challenge strain The target density of $10^{4}$ and $10^{5} \mathrm{cfu} / \mathrm{mL}$ was achieved by decimal dilution of the colorimetrically confirmed $2 \times 10^{8} \mathrm{cfu} / \mathrm{mL}$ initial suspension (2.1.2). 


\subsubsection{Animal trials}

The trial farm was prepared as stated in Section 2.1.8. Groups of 20 chicks (non-Salmonella vaccinated flocks), individually identified by wing tags, were given one of three lots of feed formulation at one day of age and throughout the trial (15 days). On day 3 post-hatch, each chick was challenged $\left(10^{4}\right.$ or $\left.10^{5} \mathrm{cfu} / \mathrm{mL}\right)$ by oral gavage $(0.250 \mathrm{~mL})$ with Salmonella Typhimurium (2.1.2). Faecal samples $(n=5)$ were collected from each pen on days 3 (prechallenge), 4, 5, 7 and 14 and cultured for the presence of $S$. Typhimurium (2.1.3). The birds were individually weighed at days 0,7 and 14. At 15 days of age (doa), all birds were humanely euthanized and their caeca removed for culture and enumeration (2.1.3 and 2.3.6).

\subsubsection{Enumeration of Salmonella}

The method employed to enumerate caecal salmonellae was the miniMPN as described in Pavic et al., (2010). Briefly, the removed caeca were cut into sections, to which BPW (w:v) was added (100 dilution). A millilitre of this dilution $\left(10^{\circ}\right)$ was added to a $1250 \mu \mathrm{L}$ plasma tube and subsequent decimal serial dilutions were prepared $(100 \mu \mathrm{L}$ into $900 \mu \mathrm{L})$ in plasma tubes.

Into appropriately labelled microtitre trays, $100 \mu \mathrm{L}$ of each dilution was added into the corresponding well using a multi-channel pipette. This resulted in the formation of a 3-tube MPN, which was covered with a plastic film (SealPlate ${ }^{\circledR}$, Excel Scientific, Inc, Victorville, CA, US) and incubated at $37{ }^{\circ} \mathrm{C}$ for $24 \mathrm{~h}$. Post-incubation, $100 \mu \mathrm{L}$ from each microtitre well was added to $200 \mu \mathrm{L}$ of modified semi-solid RV (MSRV) via a multi-channel pipette and incubated at $42{ }^{\circ} \mathrm{C} 24 \mathrm{~h}$.

All pale/white wells post incubation was confirmed using $\mathrm{SM}^{\circledR} \mathrm{ID}_{2}$ and typical colonies were confirmed serologically with Poly $\mathrm{O}$, poly $\mathrm{H}$ and anti-serogroup $\mathrm{B}$ antisera. The confirmed data set was converted to $\mathrm{cfu} / \mathrm{mL}$, using the MPN charts produced by the United States FDA (2006) from the 3 lowest positive dilutions, and calculated to MPN (cfu) per gram of caeca.

\section{Results}

\subsection{Vaccine trial}

\subsubsection{Autologous (experiment 1 ) and heterologous (experiment 2) challenge trials}

A challenge with $S$. Typhimurium, used in Experiments 1 and 2 (Table 2) to demonstrate repeatability, showed a significant difference (Mantel-Haenszel Stratified Chi squared $P<$ 0.05 ) between non-vaccinated (colonisation rates of $25 \%$ and $50 \%$ ) and vaccinated (colonisation rates of $0 \%$ and $9 \%$ ) hens. S. Typhimurium was also used in both experiments to evaluate seroconversion to the Typhimurium component of the vaccine (Table 4 and 5). The vaccinated flocks exhibited significantly higher (Student $t$-test $P<0.05$ ) titres, with $16 \%$ and $33 \%$ of blood samples having titres 85-6570 (>785 = kit positive threshold), while nonvaccinated hens gave titres of 27-176 (<460 = kit negative threshold).

After challenge, the rates of caecal colonisation (Table 2) in the non-vaccinated hens were $25 \%, 58 \%$ and $17 \%$ for serovars Typhimurium, Mbandaka and Orion respectively (Experiment 1), with an average colonisation rate of $33 \%$. In the heterologous trial 
(Experiment 2) non-vaccinated hens had an average caecal colonisation rate of $42 \%$ calculated from the individual caecal colonisation rates: Typhimurium (50\%); Agona (92\%); Infantis (17\%) and Zanzibar (9\%).

\begin{tabular}{|c|c|c|c|c|c|}
\hline $\begin{array}{l}\text { Experiment } \\
\text { number }\end{array}$ & $\begin{array}{l}\text { Vaccine } \\
\text { status }\end{array}$ & Detected & Not detected & Relative risk & Positive (\%) \\
\hline \multicolumn{6}{|c|}{ (a) Typhimurium } \\
\hline 1 & $\begin{array}{l}\text { Vaccinated } \\
\text { Non- } \\
\text { vaccinated }\end{array}$ & $\begin{array}{l}0 \\
3\end{array}$ & $\begin{array}{l}12 \\
9\end{array}$ & undefined & $\begin{array}{l}0 \\
25\end{array}$ \\
\hline 2 & $\begin{array}{l}\text { Vaccinated } \\
\text { Non- } \\
\text { vaccinated }\end{array}$ & $\begin{array}{l}1 \\
6\end{array}$ & $\begin{array}{l}10 \\
6\end{array}$ & 0.18 & $\begin{array}{l}9 \\
50\end{array}$ \\
\hline M-H analysis & Crude OR = & ; $95 \% \mathrm{CI}=$ & $69 ; \mathrm{OR}=0.06 ; x$ & $=5.73 ; P=0.017$ & \\
\hline \multicolumn{6}{|c|}{ (b) Autologous Typhimurium and heterologous Agona [B] } \\
\hline \multirow{2}{*}{2} & Vaccinated & 1 & 10 & \multirow[b]{2}{*}{0.18} & 9 \\
\hline & $\begin{array}{l}\text { Non- } \\
\text { vaccinated }\end{array}$ & 6 & 6 & & 50 \\
\hline \multirow{2}{*}{2} & Vaccinated & 5 & 7 & \multirow[b]{2}{*}{0.23} & 42 \\
\hline & $\begin{array}{l}\text { Non- } \\
\text { vaccinated }\end{array}$ & 11 & 1 & & 92 \\
\hline M-H analysis & \multicolumn{4}{|c|}{$\begin{array}{l}\text { Crude OR }=0.15 ; 95 \% \mathrm{CI}=0.1 \text { to } 0.49 ; \mathrm{OR}=0.08 ; \mathrm{X}^{2}=8.83 ; P= \\
0.003\end{array}$} & \\
\hline \multicolumn{6}{|c|}{ (c) Autologous Mbandaka [C] and heterologous Infantis [C] } \\
\hline \multirow{2}{*}{1} & Vaccinated & 1 & 11 & & 8 \\
\hline & $\begin{array}{l}\text { Non- } \\
\text { vaccinated }\end{array}$ & 7 & 5 & 0.02 & 58 \\
\hline \multirow{2}{*}{2} & Vaccinated & 0 & 10 & & 0 \\
\hline & $\begin{array}{l}\text { Non- } \\
\text { vaccinated }\end{array}$ & 2 & 10 & Undefined & 17 \\
\hline M-H analysis & $\begin{array}{l}\text { Crude OR = } \\
0.013\end{array}$ & $3 ; 95 \% \mathrm{CI}=$ & $0.62 ; \mathrm{OR}=0$ & $; \mathrm{X}^{2}=6.24 ; P=$ & \\
\hline \multicolumn{6}{|c|}{ (d) Autologous Orion [E] and heterologous Zanzibar [E] } \\
\hline \multirow[b]{2}{*}{1} & Vaccinated & 0 & 12 & & 0 \\
\hline & $\begin{array}{l}\text { Non- } \\
\text { vaccinated }\end{array}$ & 2 & 10 & Undefined & 25 \\
\hline \multirow{2}{*}{2} & Vaccinated & 0 & 10 & & 9 \\
\hline & $\begin{array}{l}\text { Non- } \\
\text { vaccinated }\end{array}$ & 1 & 10 & Undefined & 50 \\
\hline M-H analysis & $\begin{array}{l}\text { Crude OR }= \\
\text { All remaini }\end{array}$ & $\begin{array}{l}5 \% \mathrm{CI}=-; \mathrm{C} \\
\text { ens were us }\end{array}$ & $\begin{array}{l}\text { ndefined; } X^{2}= \\
\text { hegative contro }\end{array}$ & $1 ; P=0.25$ & \\
\hline
\end{tabular}

Table 2. Mantel-Haenszel stratified contingency table analysis of Salmonella caecal culture results comparing non-vaccinated and Tri-valent vaccinated $\mathrm{Cobb}^{\mathrm{TM}}$ adult breeder hens challenged $\left(10^{7} \mathrm{cfu} / \mathrm{mL}\right)$ with serovar $(\mathrm{CI}=$ confidence Interval; $\mathrm{M}-\mathrm{H}$ = Mantel-Haenszel; $\mathrm{OR}=$ odds ratio). 
The cloacal swab results (Table 3) suggested that no hens were colonised by Salmonella prior to challenge (Day 0). Three days post challenge (Day 3) the prevalence in non-vaccinated hens ranged from zero to $40 \%$ compared to zero to $10 \%$ for the vaccinated flocks, changing to $0-83 \%$ and $0-36 \%$ respectively 14 days post-challenge. The cloacal swabs (Table 3) showed that the serovar Agona colonised non-vaccinated hens the best, with prevalence of $40 \%$ (at day 3) and $83 \%$ (at day 14), and a caecal prevalence of $92 \%$. In contrast, Zanzibar did not appear to colonise (day 3 and 14), based on cloacal swabs, and a caecal prevalence of only $9 \%$.

Due to low colonisation rates (17\% and $9 \%)$, combined with the low number of replicates $(n$ $=12$ and 11), statistically valid $(P \leq 0.05)$ results could not be obtained for serogroup $\mathrm{E}$ (Table $2 \mathrm{~d}$ ). The null hypothesis could not be rejected. The statistically desired colonisation rate for non-vaccinated (50\%) was only achieved with serovars Mbandaka (Table 2c), Typhimurium and Agona (Table 2b) which all demonstrated a significant difference between vaccinated and non-vaccinated hens.

By using a stratified Mantal-Haenszal Chi squared test, comparing autologous to heterologous serovars within the same serogroup, significant differences $(P=0.003$ and 0.01$)$ were demonstrated for serogroups $B$ (Table $2 b$ ) and C (Table 2c), and respective odds ratios of 6.6 and 12.5 times for colonisation among non-vaccinated compared with vaccinated groups. However, serogroup E serovars did not demonstrate a significant difference due to the low colonisation rate of the non-vaccinated hens.

The serovar Typhimurium was used to demonstrate (Table 2a) a repeatable significant difference between non-vaccinated and vaccinated hens (Mantel-Haenszal $P=0.017$ ). All non-challenged controls were negative for the challenge and wild serovars of Salmonella.

\begin{tabular}{|c|c|c|c|c|c|}
\hline \multirow[b]{2}{*}{$\operatorname{Exp}$} & \multirow[b]{2}{*}{ serotype } & \multicolumn{4}{|c|}{$\begin{array}{l}\text { Prevalence of vaccinated }(n=12) / \text { non-vaccinated }(n=12) \text { hens at various } \\
\text { days post challenge. }\end{array}$} \\
\hline & & Day 0 & Day 3 & Day 14 & Day 21 caeca \\
\hline 1 & Typhimurium & $0 \% / 0 \%$ & $0 \% / 16 \%$ & $0 \% / 16 \%$ & $0 \% / 25 \%$ \\
\hline 1 & Mbandaka & $0 \% / 0 \%$ & $0 \% / 16 \%$ & $0 \% / 16 \%$ & $8 \% / 58 \%$ \\
\hline 1 & Orion & $0 \% / 0 \%$ & $0 \% / 16 \%$ & $0 \% / 16 \%$ & $0 \% / 16 \%$ \\
\hline 2 & Typhimurium & $0 \% / 0 \%$ & $8 \% / 25 \%$ & $9 \%(11) / 25 \%$ & $9 \%$ (11) / 50\% \\
\hline 2 & Agona & $0 \% / 0 \%$ & $10 \% / 40 \%$ & $36 \% / 83 \%$ & $42 \% / 92 \%$ \\
\hline 2 & Infantis & $0 \% / 0 \%$ & $0 \% / 20 \%$ & $0 \%(10) / 8 \%$ & 0\% (10) / 17\% \\
\hline 2 & Zanzibar & $0 \%(10) / 0 \%(11)$ & $0 \%(10) / 0 \%(11)$ & $0 \%(10) / 0 \%(11)$ & $0 \%(10) / 9 \%(11)$ \\
\hline
\end{tabular}

Prevalence without bracketed numerals were calculated from $n=12$ as compared to $n=(\mathrm{x})$. All groups initially contained 12 birds and bird death was due to non-trial related illness.

Table 3. Salmonella serovars prevalence from cloacal swabs (0, 3 and 14 days) and caeca (21 days) post challenge ( $\left.10^{7} \mathrm{cfu}\right)$ from adult $\mathrm{Cobb}^{\mathrm{TM}}$ breeder broiler hens in Experiments 1 and 2.

\subsubsection{Experiment 1 autologous serology}

The blood samples taken from all hens prior to challenge demonstrated that vaccinated hens contained variable levels of antibodies to Salmonella. This is illustrated by the wide range of 
titres (1161 \pm 623 at the $95 \%$ confidence intervals from mean) from the x-OVO Guildhay Salmonella Typhimurium ELISA test (Table 4). All the unvaccinated flocks had titres well below the negative cutoff value. Blood samples from tri-vaccine vaccinated hens $(n=30)$ were tested, using the $x-O V O$ Guildhay Typhimurium and Idexx Typhimurium-InfantisEnteritidis ELISA, showing a $1: 0.8$ ratio respectively (x-OVO Guildhay Typhimurium ELISA average OD $=0.39$ and Idexx Typhimurium: Infantis: Enteritidis ELISA average OD $=0.70$ in positive wells), which was highly significant (Student $t$-test $P=0.0001$ ). All blood sera positive for anti-Infantis antibodies contained anti-Typhimurium antibodies.

\begin{tabular}{ccc}
\hline Blood serum result & $\begin{array}{c}\text { Typhimurium titre mean } \\
(95 \% \text { confidence limits })\end{array}$ & Coefficient of variation \\
\hline \hline Non Vaccinated titre $(n=50)$ & $130( \pm 27)$ & $60 \%$ \\
Vaccinated titre $(n=50)$ & $1161( \pm 623)^{\mathrm{A}}$ & $127 \%$ \\
\hline
\end{tabular}

A Means without common superscripts differ significantly (Student $t$-test $<0.05$ ).

Table 4. Anti-Salmonella Typhimurium antibody titres means, with 95\% confidence limits, for vaccinated and non-vaccinated $\mathrm{Cobb}^{\mathrm{TM}}$ adult breeder hens (Experiment 1).

The large co-efficient of variation reflects variation in seroconversion among the vaccinated birds, with $16 \%$ of those vaccinated demonstrating titres $>785$ and $25 \%$ with titres $>460$ (true negative). There was a statistically significant difference (Student's two-tailed $t$-test, $P$ $<0.05)$ in anti-Salmonella antibody levels between vaccinated and non-vaccinated flocks.

\subsubsection{Experiment 2 heterologous serology}

Half of the vaccinated group in Experiment 2 were individually tagged and bled prior to vaccination at 12 and 17 weeks of age (Table 5). Hens at 18 weeks had developed significant (Fisher exact $P=0.001$ ) serum antibodies to $S$. Typhimurium compared to hens prior to vaccination (12 weeks), but not to hens in other age groups. Hens at 20 weeks of age had developed a significant difference in antibody to all age groups $(P=0.0005$ and 0.01$)$ with the exception of 18 week olds.

\begin{tabular}{ccccc}
\hline Hen Age (weeks) & Titre $<785$ & Titre $>$ 785 & Total & Positive (\%) \\
\hline \hline 12 & 25 & 0 & 25 & $0 \% \mathrm{~A}$ \\
14 & 22 & 2 & 24 & $8.33 \% \mathrm{AB}$ \\
16 & 22 & 2 & 24 & $8.33 \% \mathrm{AB}$ \\
18 & 17 & 6 & 23 & $26 \% \mathrm{BC}$ \\
20 & 14 & 9 & 23 & $43 \% \mathrm{C}$ \\
\hline
\end{tabular}

AB Percentages without common superscripts differ significantly (Fisher Exact $P<0.05$ ). Mortalities of hens at 14 and 18 weeks were due to non vaccine-related causes (Femoral Head Necrosis).

Table 5. Anti-Salmonella Typhimurium antibody titres in vaccinated hens $(n=25)$ prior to (12 weeks), during (12 to 17 weeks) and after (18 to 20 weeks) the vaccination protocol (Experiment 2). 
After the first vaccination, initial sero-conversion was observed in two $(8.33 \%)$ of the hens $(n=24)$. Unfortunately, one of those hens died at 18 weeks, whereas the other hen had titres of 812,1222, 1200 and 1114 at weeks 14, 16, 18 and 20 respectively, and this hen was also negative for presence of Salmonella in its caeca post-challenge. The percentage 'true' (titre > 785) positive was $26 \%$ or $34 \%$ if the ELISA (2.1.7) kits 'suspect' interpretations were included. When these hens were randomised and challenged at 20 weeks of age the percentage of serum positive birds was $43 \%$, or $60 \%$, including 'suspect' reactions. The titre range in the second experiment was more precise with a mean titre of $1016 \pm 546(95 \% \mathrm{CI})$ and a low co-efficient of variation (26\%).

The percentage of eggs that had antibodies against $S$. Typhimurium was $16 \%$ (titre $>785$ ), or $48 \%(n=61)$ if 'suspects' (titre 460 to 784) were included. Titres ranged from 145 to 1890 for egg yolks from vaccinated hens compared with a range of 332 to 427 (below ELISA kit negative < 460) for non-vaccinated hens eggs. Regardless of the low number of ELISA positives (titres $>785$ ) from eggs originating from vaccinated hens, there was still a significant difference $(P=0.001)$ between egg yolk anti-Typhimurium titres from nonvaccinated as compared to vaccinated hens.

\subsubsection{Maternal antibody protection (experiment 3)}

All chicks (except non-vaccinated and non challenged control and vaccinated nonchallenged control) were challenged at day 0 and appeared healthy and gained weight.

Initial serological testing from a culled group $(n=24)$ resulted in negative titres $(<460)$ and chick paper culture was negative for Salmonella for both non-vaccinated and vaccinated flocks. There was one chick from the vaccinated $10^{8}$ and non-vaccinated $10^{4}$ (Table 6) which died from conditions unrelated to the trial (Femoral Head Necrosis).

\begin{tabular}{ccc} 
Groups & \multicolumn{2}{c}{ 21 day old caecal Salmonella } \\
Vaccine status / challenge level & Detected & Not detected \\
\hline \hline AVaccinated / $10^{8} \mathrm{cfu}$ & 19 & 0 \\
ANon-vaccinated / $10^{8} \mathrm{cfu}$ & 20 & 0 \\
BVaccinated / $10^{4} \mathrm{cfu}$ & 15 & 5 \\
ANon-vaccinated / $10^{4} \mathrm{cfu}$ & 19 & 0 \\
\hline
\end{tabular}

The vaccinated / non challenged $(n=10)$ and non-vaccinated / non challenged $(n=10)$ controls were all negative for Salmonella. Groups without common superscripts differ significantly (Fisher Exact $P \leq$ 0.05). One chick died from a non-trial related cause (Femoral Head Necrosis) in both the vaccinated $10^{8}$ and non-vaccinated $10^{4}$ group. There were no differences between cloacal swab results from days 3,14 and 21.

Table 6. Salmonella vaccinated $(n=50)$ and non-vaccinated $(n=50)$ progeny protection from $S$. Typhimurium challenge at high $\left(10^{8} \mathrm{cfu}\right)$ and low $\left(10^{4} \mathrm{cfu}\right)$ dose.

The cloacal swab results from randomly chosen chicks $(n=5)$ were all positive 3 days post challenge for $S$. Typhimurium, during the grow-out phase (day 14 swabs) and caecal culture results (day 24) when the birds were challenged with $10^{8} \mathrm{cfu}$ Salmonella.

The cloacal swabs and caecal cultures revealed a significant difference (Fisher exact $P=$ 0.047 ) between chicks challenged with $10^{4} \mathrm{cfu}$ of $S$. Typhimurium, which were progeny, of 
vaccinated hens ( $75 \%$ positive) compared to progeny from non-vaccinated (100 \% positive) hens at 3, 14 and 24 days of age (Table 6). The serology results, initially and at 21 days post challenge, indicated negative $S$. Typhimurium antibody titres $(<460)$ for both vaccinated and non-vaccinated chicks.

\subsubsection{Longitudinal analysis}

The comparison of the prevalence of Salmonella, at genus level and within flocks, was performed by plotting the monthly drag swab relative prevalence (positive flocks / total flocks tested in each month) one year prior to vaccination (2003), during vaccination (2004) and subsequent vaccination (2005).

The prevalence of Salmonella in 2003 was $52 \%$, decreasing to $41 \%$ in 2004 and $40 \%$ in 2005 (Figures 1 and 2). The first flocks vaccinated were 12 weeks of age as of the 1/1/2004, designated with an arrow (Figure 1). For each month post vaccination the 'forecast' relative prevalence (Figure 1) was calculated (Excel, forecast function using the previous 12 months prevalence data to calculate the predicted value).

The year prior to vaccination (Figure 1) showed peaks and troughs in flock prevalence, which followed seasons (lowest prevalence in winter and higher prevalence in summer). As the flocks were vaccinated, the monthly prevalence levels decreased and the monthly variation flattened; a moderate linear association $\left(\mathrm{R}^{2}=0.56\right)$ was found, compared to 'forecast' values $\left(\mathrm{R}^{2}=0.16\right)$ (Figure 1$)$.

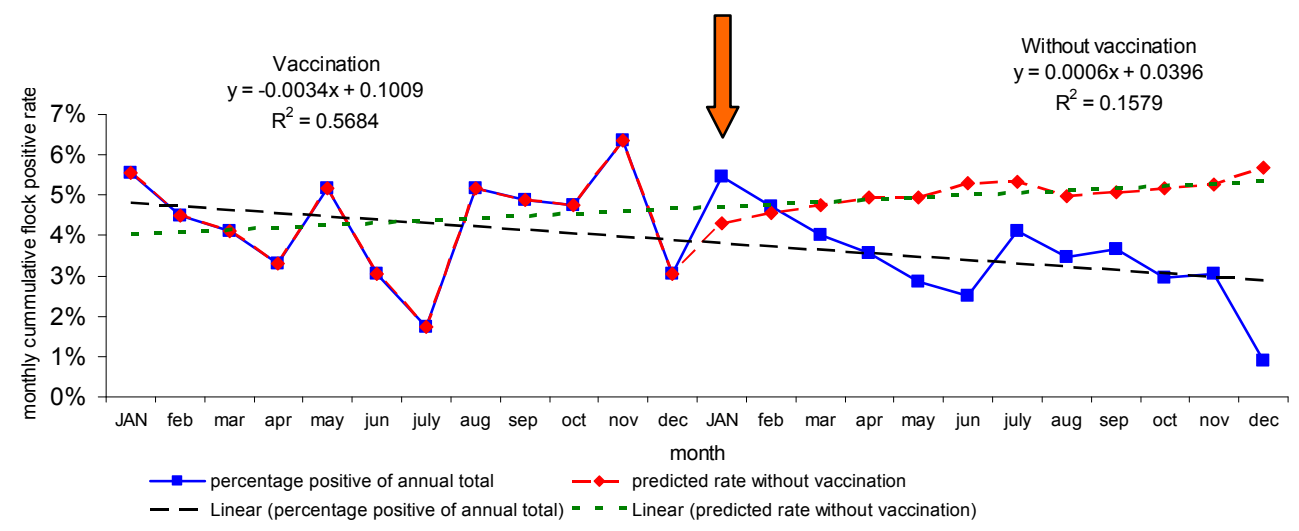

Fig. 1. Salmonella flock monthly prevalence $(\%)$ in Breeders during the years $2003(n=794)$ to $2004(n=1024)$ with the arrow indicating when vaccination started and forecast data (Red line) used to show the predicted prevalence if vaccination was not introduced. 


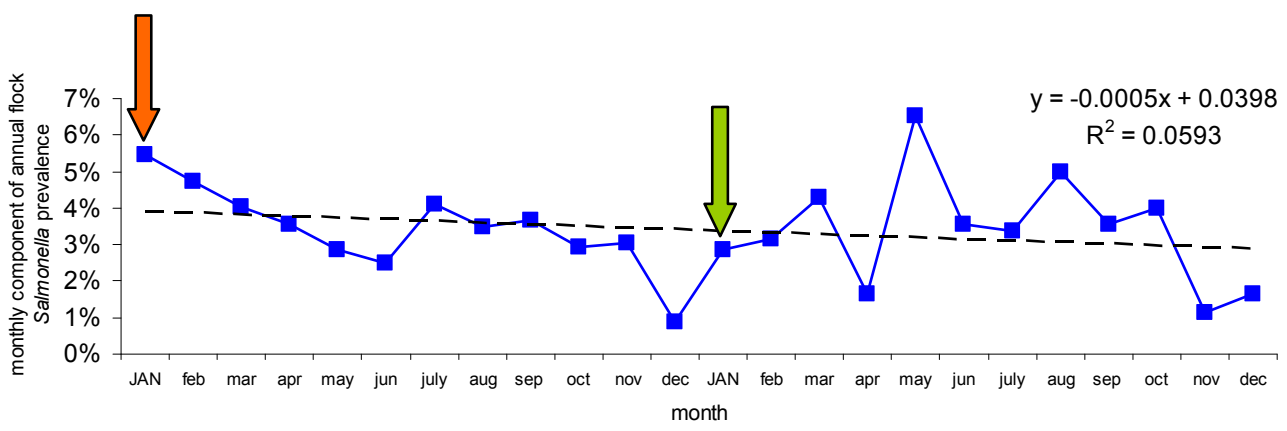

$\rightarrow$ - percentage positive from annual total - Linear (percentage positive from annual total)

Fig. 2. Salmonella flock monthly prevalence (\%) in Breeders during the vaccinations years $2004(n=1024)$ to $2005(n=968)$. The two arrows indicate the start of vaccination and the month when all flocks were vaccinated.

Serogroup B

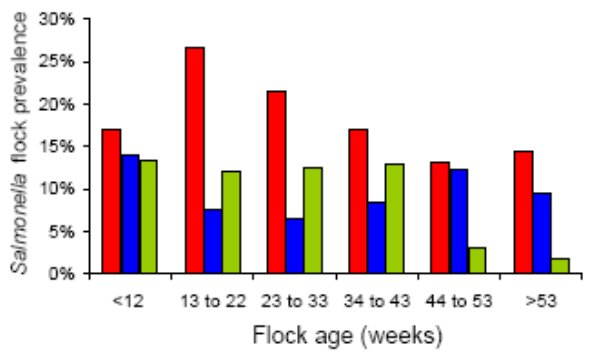

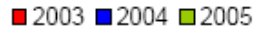

Serogroup E

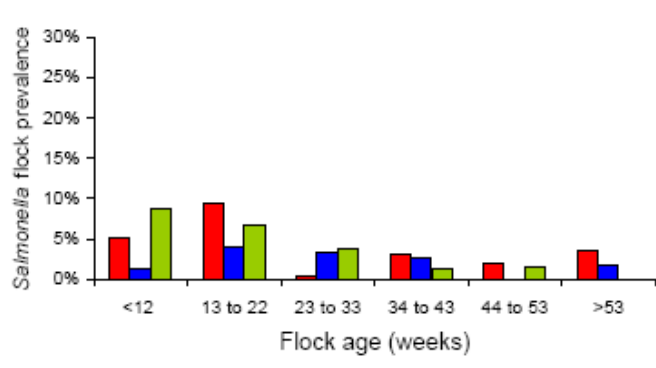

ロ2003 $2004 \square 2005$
Serogroup C

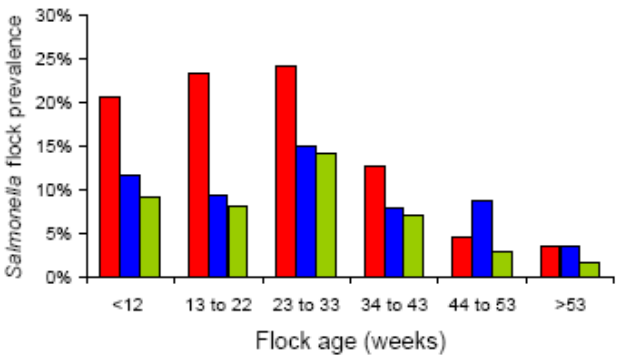

ロ2003 —2004 2005

Non Vaccine Serogroups

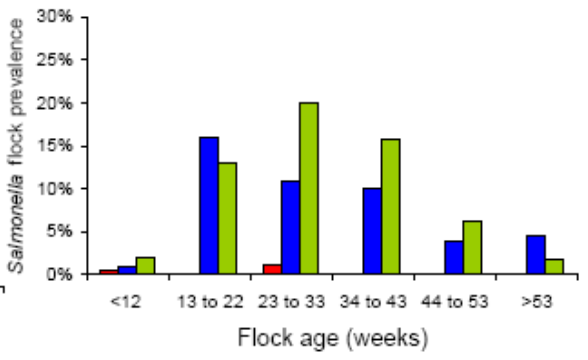

—2003 —2004 2005

Fig. 3. The prevalence rate in tri-valent vaccine-relevant serogroups in breeders, based upon flock age for the pre-vaccinated year $2003(n=794)$ and the vaccinated years $2004(n=1024)$ and $2005(n=968)$ with vaccination occurring at 12 and 18 weeks of age. 
The variation in sample size, 794 (2003), 1024 (2004) and 968 (2005), was due to more intensive testing in the first year of vaccination. The flock prevalence rate between 2004 (40 $\%)$ and 2005 (41 \%) remained static, which was corroborated by a $\mathrm{R}^{2}$ (linear) of almost zero (Figure 2). The spikes observed in the latter half of 2005 (Figure 2) were due to the unplanned introduction of non-vaccinated Salmonella-positive males, at 20 weeks of age, to other breeder farms.

The results in Figure 3 demonstrate an interesting trend in the prevalence for the years in which the vaccine e was administered (2004 and 2005, blue and green bars) compared to the year prior (2003, red bar). The prevalence of Salmonella from serogroups B, C and E decreased post-vaccination while increases among non-vaccine serogroups were observed, with serovar subsp 1 rough:r:1,5 predominating (Table 7).

\begin{tabular}{ccccc}
\hline & & \multicolumn{3}{c}{ Year } \\
sero-group & Serovar & 2003 & 2004 & 2005 \\
\hline \hline B & Agona & & & \\
B & Subsp 1 ser 4,12:d:- & $5.0 \%$ & $6.0 \%$ & $5.8 \%$ \\
B & Typhimurium & $15.2 \%$ & $7.2 \%$ & $9.03 \%$ \\
C1 & Infantis & $29.2 \%$ & $26.0 \%$ & $18.6 \%$ \\
C1 & Livingstone & $6.1 \%$ & $0.5 \%$ & $0.21 \%$ \\
C1 & Mbandaka & $4.9 \%$ & $6.0 \%$ & $6.6 \%$ \\
C1 & Singapore & $0.6 \%$ & $0.9 \%$ & $0.24 \%$ \\
C2 & Bovismorbificans & $12.6 \%$ & $3.3 \%$ & $3.61 \%$ \\
C2 & Muenchen & $0.6 \%$ & $0.23 \%$ & $1.51 \%$ \\
E1 & Orion & $2.2 \%$ & $0.23 \%$ & $0.4 \%$ \\
E1 & Zanzibar & $3.8 \%$ & $5.2 \%$ & $6.2 \%$ \\
E4 & Seftenberg & 0.6 & $2.0 \%$ & $4.7 \%$ \\
& Subsp 1 ser rough:r: 1,5 & $0.6 \%$ & $23 \%$ & $14.6 \%$ \\
& percentage total & $97.0 \%$ & $88.56 \%$ & $71.9 \%$ \\
& total positive flocks & 412 & 420 & 387 \\
\hline
\end{tabular}

Table 7. Flock Salmonella serovar trend for the year prior, $2003(n=794)$, and the years postvaccination, $2004(n=1024)$ and $2005(n=968)$.

During and subsequent to vaccination there was a change in the profile of serovars isolated from breeder flocks (Table 7). The vaccine serogroups all decreased with the exception of Mbandaka (serogroup C). This increase could be explained by early colonisation prior to vaccination (Figure 4). Table 7 shows serovar succession, which may have occurred post vaccination.

Prior to vaccination (2003) there were 13 serovars that accounted for $97 \%$ of all positives (Table 7). This figure decreased to $88.9 \%$ (2004) and $71.9 \%$ (2005) when all flocks were vaccinated. There was also a major change in the predominant serovar with rough: $r: 1: 5$ increasing from $0.6 \%$ (2003) to $23 \%$ (2004) and $14.6 \%$ (2005), both significantly different $\left(\chi^{2}\right.$ $P=0.0001)$. Beside those in Table 7, the serovars isolated were: in 2003 Lille (1.2\%), Ohio 
(0.6 \%), subsp. 1 ser 16:I; ; - $(0.6 \%)$ and Tennessee (0.6 \%); 2004 and 2005 Anatum $(0.5 \%$ $\{2004\}, 1 \%\{2005\})$, Chester $(0.6 \%, 1.2 \%)$, Give (1.6 \%, $2.0 \%)$, Havana (0.6 \%, $5 \%)$, Javiana $(0.6 \%, 1.5 \%)$, Kiambu (1.5\%, $3 \%)$, Lillee $(1.5 \%, 1 \%)$, Ohio $(1.2 \%, 1.9 \%)$, Subsps 1 ser 16:I;v;- (1.5 \%, $3.5 \%)$, Subsps 1 ser 6,7:r:- $(0.6 \%, 0 \%)$, Worthington (1.6 \%, 0 \%), Bredeney (0 $\%, 2 \%)$, Cubana $(0 \%, 3.5 \%)$ and Tennessee $(0 \%, 2 \%)$.

There was no overall change in prevalence of serogroup $\mathrm{C} 1$ (Table 7); while the $\mathrm{C} 1$ positive flocks were all positive prior to vaccination at a steady $5 \%$ prevalence rate, there was a shift in serovar prevalence, with a decrease in Infantis, the vaccine-homologous serovar.

Results suggest marginal heterologous serovar protection as shown by the steady decrease in Agona (serogroup B) post-vaccination. This decrease was similar to that for Typhimurium, observed over the same time period, and may explain the reduction in total prevalence observed during the field trial (Figure 1).

The seroconversion of birds to the vaccine Typhimurium component was routinely measured (ELISA) at the ages mentioned in Figure 4, and the mean $(n=12)$, with $95 \%$ confidence limits, was recorded. The green (line) and the red (line) indicated the Typhimurium ELISA positive and negative titres levels respectively (Figure 4).

The ELISA results (Figure 4) showed a high degree of variability in seroconversion, indicated by the very large error bars (95\% confidence). The level of flock immunity (number of sera tested that had Typhimurium ELISA titres $>785$ ) for each age group (Figure 4) during 2004 (2005) was $23 \%$ (27\%); $15 \%$ (17\%); $11 \%$ (11 \%) and $3 \%$ (6.4 \%). The average flock immunity for 2004 and 2005 was (titre $>785$ positive level) $28 \%$ and $27 \%$ respectively or $40 \%$ and $37 \%$ if the titre was calculated at $>460$ (negative level).

The 2005 trend line had a dip at 23 to 32 weeks of age; only 21 flocks ( 272 sera) were tested in 2004 compared to 135 flocks (1345 serums) tested in 2005, which affected the average. This large discrepancy in flocks tested in this age group (2004 and 2005) was not observed in any other age group during the same period (2004 to 2005).

The titre profile shown in Figure 4 for all flocks was also apparent when the titres of the individual flocks were examined over the same time period (categorized by weeks of age\{woa\}). They all showed a similar age titre profile (Figure 4; year 2004) with a shoulder period (ages 13 to 22 and 23 to 32) and then a decrease with age.

An investigation into the efficacy of the tri-vaccine on juvenile ( $<6$ woa) breeder flocks (grown day old to death, rearing and production), already colonized by serovar Typhimurium $(n=32)$, was undertaken during 2004 to 2005. All these Typhimurium positive flocks (determined using drag swabs) were routinely sampled, as mentioned previously, and the drag swabs were compared to the anti-Typhimurium titre for the same age groups. A flock was deemed negative if two consecutive drag swabs did not contain the Typhimurium serovar, and the initial age recorded (i.e. 6 woa $=$ Typhimurium positive; 12 woa $=$ positive; $18 \mathrm{woa}=$ positive; $22 \mathrm{woa}=$ positive; $33 \mathrm{woa}=$ negative $; 3 \mathrm{woa}=$ negative and 53 woa $=$ negative, the age negative is 33 woa).

The corresponding Typhimurium titre was also measured and the flock average over the sampling period was recorded. The data summarized in Figure 5 show a random and variable Typhimurium clearance rate in flocks with low $(<1000)$ anti-Typhimurium antibody means, with only two flocks clearing the serovar prior to production age $(>25$ 


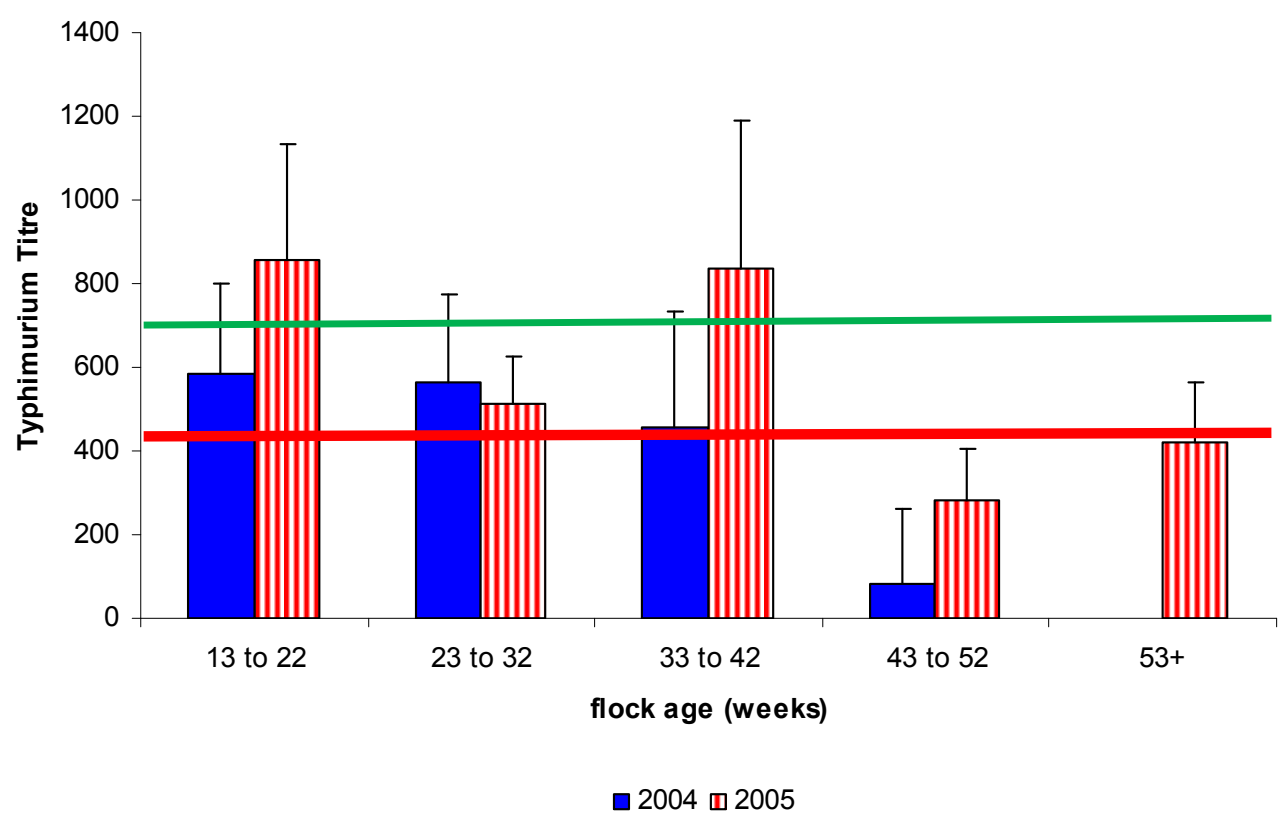

Fig. 4. Flock seroconversion of the Typhimurium component (positive \{green line\} and negative \{red line\} ELISA thresholds) of the Tri-vaccine as measure by anti-Typhimurium ELISA ( $95 \%$ confidence limits) from flock $(n=12)$ bloods taken at various ages between 2004 and 2005.

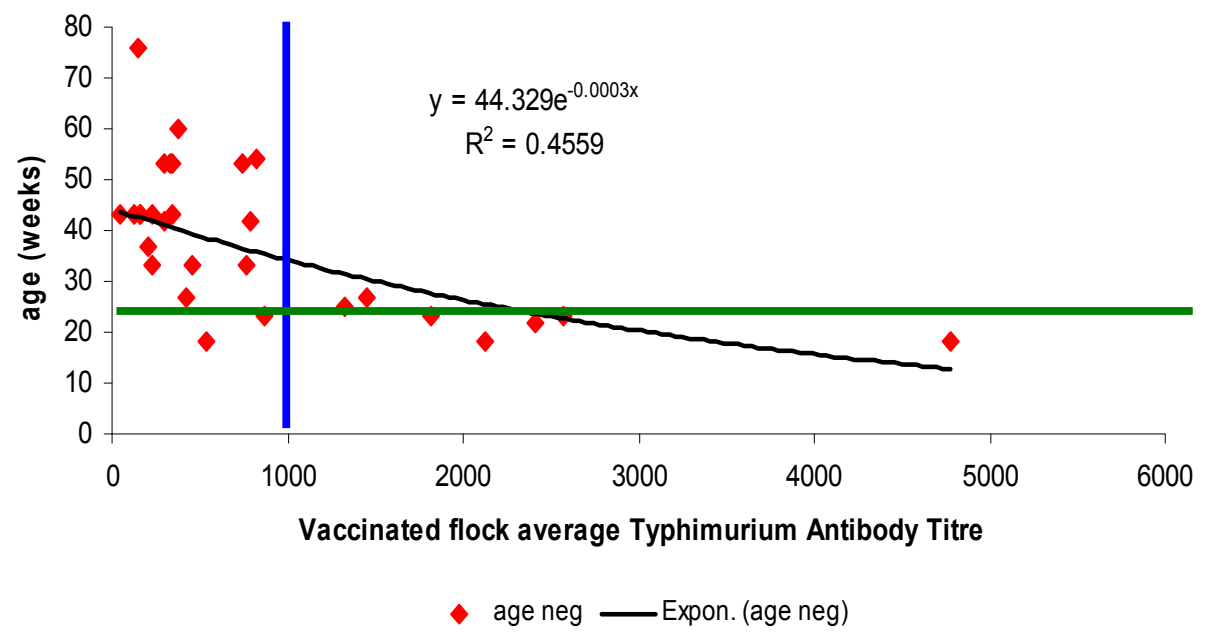

Fig. 5. Naturally Typhimurium colonised chicks (2004 to 2005), grown in day old to death houses, clearance age (weeks) in relation to the flock mean $(n=12)$ anti-Typhimurium titre trend (exponential $\mathrm{R}^{2}$ ), measured post vaccination (12 and 18 weeks), with critical limits set at hen age of 25 weeks (green line) and mean titre $>1000$ (blue line). 
woa). Six of seven flocks with high titre $(>1000)$ were clear of Typhimurium at production age ( $<25$ woa). These flocks with high titre means $(>1000)$ also had high $(75 \%, n=12)$ flock immunity (anti-Typhimurium titre $>850$ ).

The data in Figure 5 were analyzed using an exponential trend line, which showed a moderate association $\left(\mathrm{R}^{2}=0.45\right)$ that, when converted to a $2 \times 2$ contingency table (Table 8$)$, was highly significant $\left(X^{2} P=0.0002\right)$ between titre and Typhimurium clearance. Additionally, Typhimurium colonized flocks were 17.5 times more likely to remain colonized after 25 woa, if their titres were below 1000.

\begin{tabular}{cccc}
\hline Typhimurium titre & Negative at $<25$ & Positive at $\mathbf{2 6}$ & Total \\
\hline \hline High $>1000$ & 6 & 1 & 7 \\
Low $<1000$ & 2 & 23 & $\mathbf{2 5}$ \\
total & $\mathbf{8}$ & $\mathbf{2 4}$ & $\mathbf{3 2}$ \\
\hline
\end{tabular}

Fisher exact $P=0.0002$ with an odds ratio of 140 and a relative risk of 17.5 .

Table 8. The Chi squared analysis comparing high $(>1000)$ and low $(<1000)$ mean $(n=12)$ anti-Typhimurium titres in pre-vaccinated Typhimurium positive flocks that had consecutive negative drag swabs at 25 weeks of age.

\subsection{Immunoprophylaxis trial}

\subsubsection{IgY analysis}

ELISA analysis of the breeder egg yolks from three different farms showed that all the flocks had high flock immunity (number of samples titre $>785$ in serum sample divided by total tested) and a high mean flock titre (Table 9). The crude IgY yield (Figure 6) ELISA results (Figure 7) showed a high variance in Typhimurium antibodies (15\% to $80 \%>785$ and means of 343 to 2518) deposited in egg yolks tested $(n=20)$ which was further investigated using Farm 1 yolks (Figure 8).

\section{$\begin{array}{lll}\text { Farm 1 } & \text { Farm 2 } & \text { Farm 3 }\end{array}$}

Flock Typhimurium serum (IgY)

mean $(95 \% \mathrm{CI})$

Flock Immunity rate

Egg Typhimurium IgY positive rate

$\begin{array}{lll}1118( \pm 502) & 1844( \pm 528) & 2104( \pm 564) \\ 70 \% & 85 \% & 100 \% \\ 15 \% & 26 \% & 80 \% \\ 343( \pm 143) & 761( \pm 276) & 2518( \pm 1361) \\ 28( \pm 8) & 32( \pm 12) & 26 \quad( \pm 4) \\ 153( \pm 118) & 386( \pm 286) & 690( \pm 390)\end{array}$

Table 9. Summary of Salmonella Typhimurium vaccinated donor flocks for mean $(95 \% \mathrm{CI})$ antibody titres, from serum $(n=12)$, egg yolk $(n=20)$ and crude extract $(n=20)$, flock immunity (percentage of sera with titre $>785)$, yolk positive rate (No. of yolks $>785$ titre) and crude IgY yield (mg/g). 


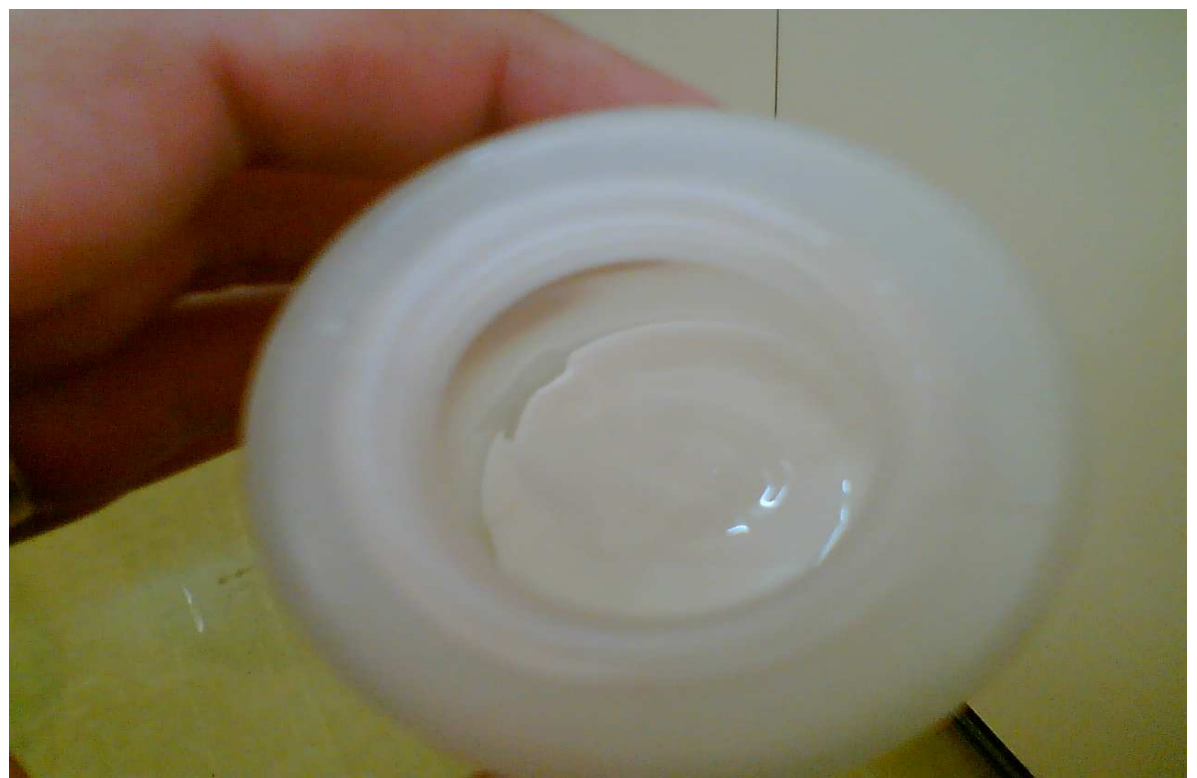

Fig. 6. Salt precipitated crude IgY containing Typhimurium antibodies, which were extracted from vaccinated breeder hen's eggs.

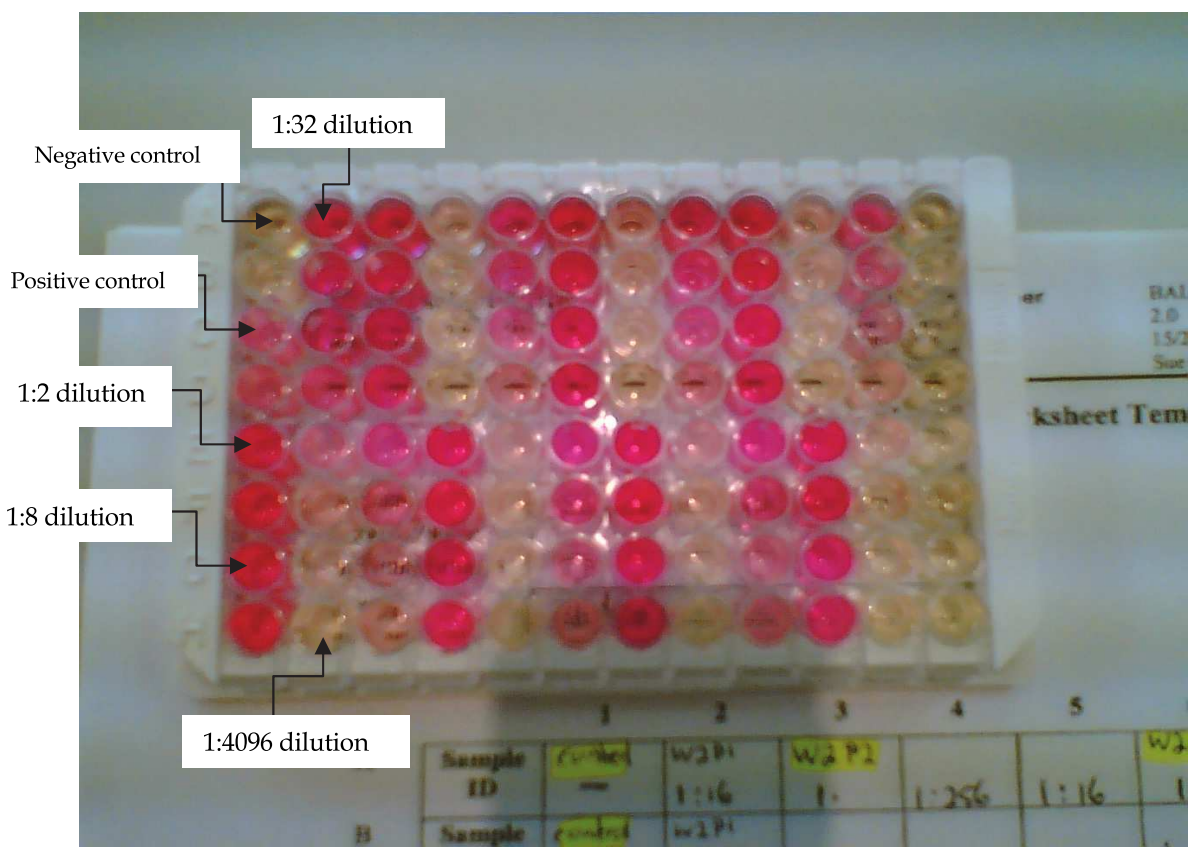

Fig. 7. Salmonella Typhimurium ELISA plate, using doubling dilution, to determine the crude IgY titre from egg yolk extract. 


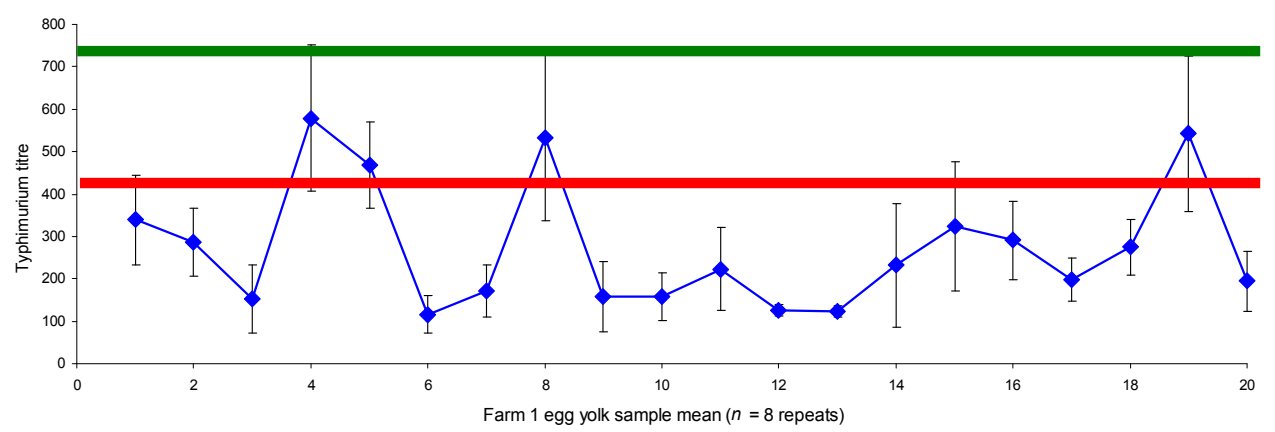

Fig. 8. Variability in anti-Typhimurium ELISA (positive $>785$, green line, and negative $<$ 459 , red line) titre means $(n=8,95 \% \mathrm{CI})$ in eggs $(n=20)$ from Farm 1 . The data portrayed in Figure 8 show a very large variance in the Typhimurium antibody levels present in Farm 1 egg yolks. Only egg yolks 4, 8 and 19 had Typhimurium titres levels close to the ELISA positive range of $>785$. The majority of yolks, with the exception of yolks 1,5 and 15, were below the negative level of $<459$.

Of the yolks from the three farms, composited post-freeze drying, anti-Typhimurium antibodies (titre $>785$ ) were present in $90 \%$ of the samples tested. The titres in the composites ranged from 16 to 1024 with a mean $( \pm 95 \% \mathrm{CI})$ of $386( \pm 203)$. The egg yolk composited crude extract (Figure 7) resuspended in PBS (5 mL per yolk), had an IgY titre of 256.

\subsubsection{IgY feed trial}

The results of the net body weight gain for these four feeding regimes are summarised in Figure 9 which showed that there was no significant difference (Student $t$-test $>0.05$ ) for all the feeds regardless of Typhimurium challenge dose and at various ages ( 0,7 , and 14 doa).

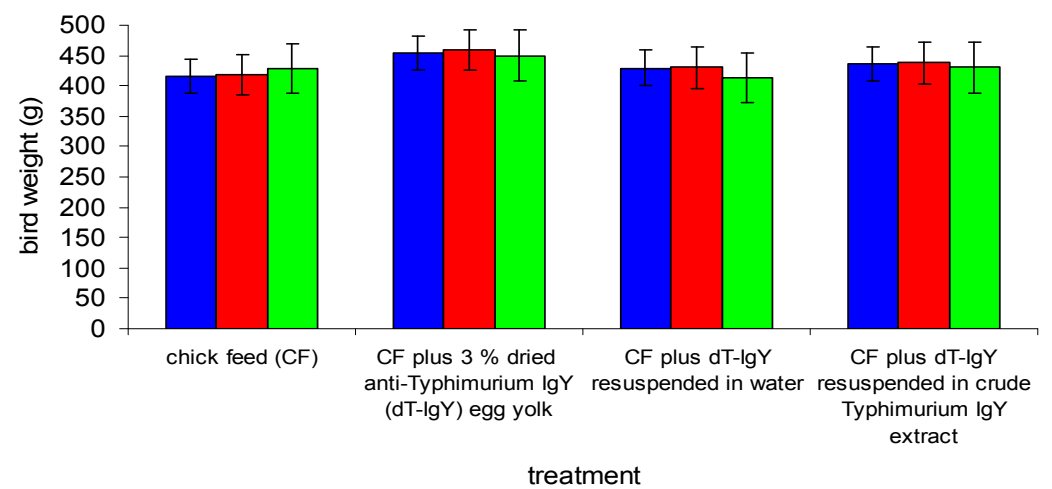

$\square$ Typhimurium Challenge $10^{\wedge} 4 \mathrm{cfu} / \mathrm{ml} \square$ Typhimurium challenge $10^{\wedge} 5 \mathrm{cfu} / \mathrm{ml} \square$ No Challenge

Fig. 9. The net body weight gain (after 15 days) of challenged $\left(10^{4}\right.$ or $10^{5} \mathrm{cfu} / \mathrm{mL}$ of $S$. typhimurium) chicks fed with four rations. 
The rehydrated dT-IgY was fed to the chicks initially by hand (smearing of dT-IgY paste on the beak) with the remainder of the feed spread out in a line on chick paper. Only when all this feed was consumed was the standard ration introduced. This ensured that all the rehydrated dT-IgY was consumed.

The residual treated feed was tested for the presence of Typhimurium antibody. The results, summarised in Figure 10, show that the chicks in the treatment groups received antiTyphimurium IgY, in various degrees, throughout the trial.

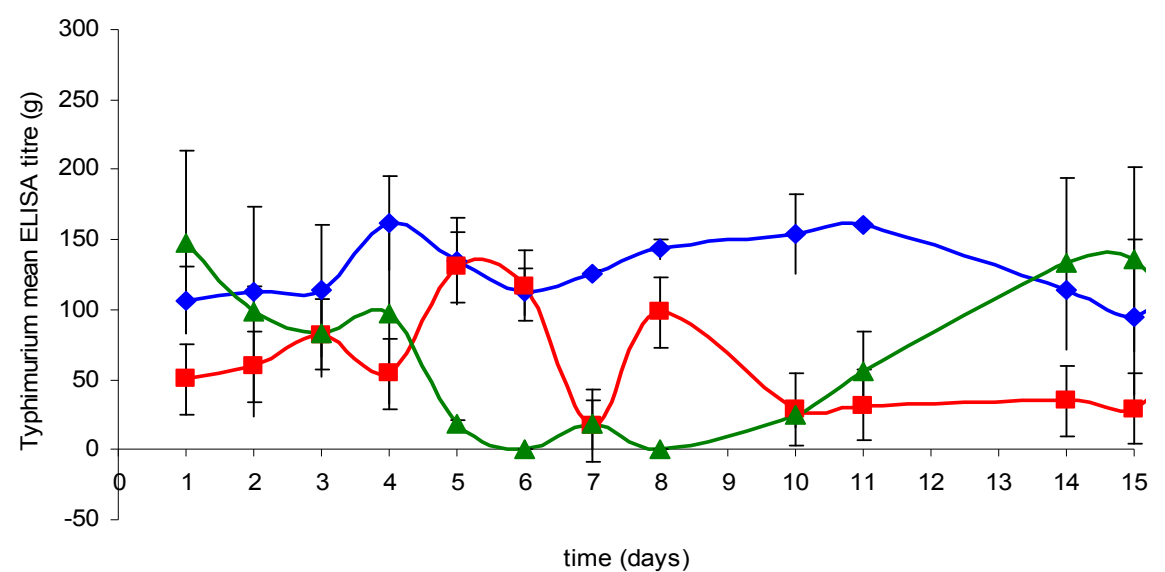

$\multimap$ yolk IgY resuspended in crude IgY $\rightarrow$ yolk IgY resuspended in water $\rightarrow$ yolk $\lg Y$ mixed in dry feed

Fig. 10. Typhimurium antibody titre $(95 \% \mathrm{CI})$ of three treated feed rations: $(\mathrm{CF})$ plus $3 \%$ (w:w) freeze dried Typhimurium IgY (dt-IgY) yolk (green line); CF plus dT-IgY resuspended in water (w:v) (red line) and dT-IgY resuspended in crude Typhimurium IgY extract (w:v) (blue line) feed prior (3 days) and post (4 days of age + ) Typhimurium ( $10^{4}$ or $10^{5} \mathrm{cfu} / \mathrm{mL}$ ) challenge.

The data summarised in Figure 10 showed that the dT-IgY resuspended in crude IgY extract (blue line) had the highest and most consistent titres, with a range 80 to 160 and a mean of 110, throughout the trial. The dT-IgY resuspended in water (red line) had the highest titre range of 50 to 130 and a mean of 60 . Finally, the dT-IgY egg yolk powder (green line) treatment was the most inconsistent with a titre range of 0 to 150 and a low mean of 61 .

The final analysis was to measure the effect of these feed treatments on $S$. Typhimurium levels in the caeca. The data summarised in Figure 11 show that, regardless of treatment, there was no significant (Student $t$ test $>0.05$ ) reduction in caecal Typhimurium populations as compared to the control. This was also observed in faecal (days 4, 5, 7 and 14) and caecal samples that were $100 \%$ positive when tested qualitatively for Salmonella presence. 


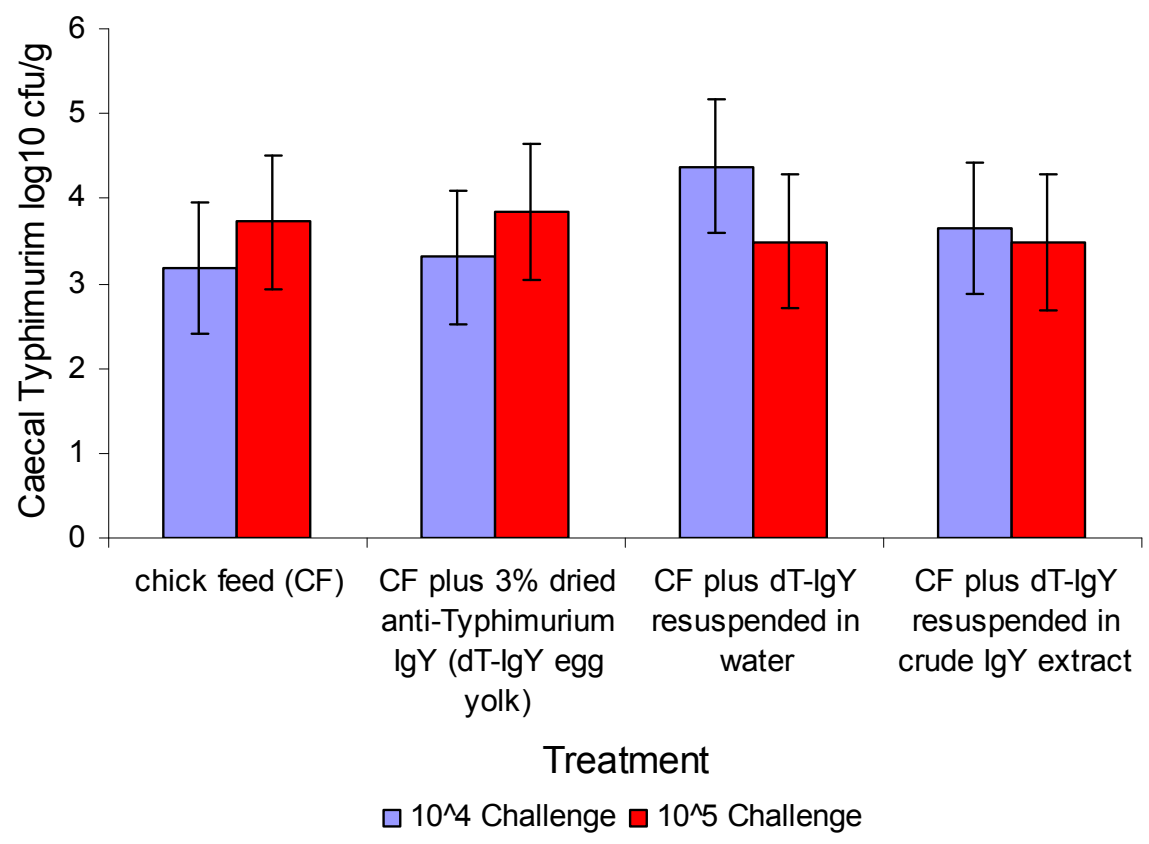

Fig. 11. S. Typhimurium caecal counts $\left(\log _{10} \mathrm{cfu} / \mathrm{g}\right.$, $\left.95 \% \mathrm{CI}\right)$ from challenged $\left(10^{4}\right.$ or $10^{5}$ $\mathrm{cfu} / \mathrm{mL}$ ) chicks on three feed treatments.

\section{Discussion}

\subsection{Vaccine trial}

One of the objectives behind developing and using a multivalent vaccine was to reduce carriage and shedding of otherwise prevalent salmonellae, and thus to protect the progeny from egg contamination and from colonisation by low level (<100 cfu) environmental and / or feed exposure (Anonymous, 2004; Franco, 2005; Volkova et al., 2009). The protection of poultry against Salmonella infection is largely empirical, based upon experimental trial work and field studies (Anonymous, 2004). Knowledge relating to the course of the innate and adaptive response to colonisation with various Salmonella types is beginning to increase (Anonymous 2004; Beal and Smith 2007). To be suitable for use in industry, a vaccine must be safe for poultry and other species, and not interfere with detection of Salmonella, as well as effective in eliminating shedding and enhancing clearance (Anonymous 2004).

With the above definition in mind the decision to use the predominant serovar from each of serogroups B, C and E was based upon success of this approach with serovars Typhimurium and Enteritidis in a European study (Van Den Bosch 2003), and serogroups C and $\mathrm{E}$ were added primarily to offer protection against the prominent Australian poultry serogroups (Davos, 2005) and, secondarily, to expand the knowledge base (Anonymous, 2004,). There were no serovars from serogroup D included in this vaccine as Australian commercial flocks are free of this serogroup (due to zero tolerance), including serovars Enteritidis, Pullorum and Gallinarum (Arzey, 2005). 
According to Grimont and Weill (2007) only 30 serovars account for $90 \%$ of Salmonella isolates in any given country. In the Australian broiler industry, typically ten different serovars account for $84 \%$ of all isolates (Davos, 2007). To suit inevitable changes in serovar prevalence, killed vaccines such as the trivaccine in the present study are most suitable for industrial use as they can be more easily prepared and therefore more readily adapted than attenuated strain vaccines.

Prior to 2008, due to consumer fears about genetically modified organisms (GMOs), in the food supply, only killed Salmonella vaccines were available for commercial use in Australia (Anonymous, 1999). The next stage of development would include vaccination with killed and attenuated Salmonellae to target both cell mediated and humoral immunity.

Bailey et al. (2007a) showed increased IgG and IgA production in serum, the gut and crop of adult broiler breeders after administered of a live followed by a killed vaccine, when compared to a killed or attenuated vaccine alone. Attenuated vaccines can be given to dayold chicks, providing competitive exclusion and stimulating polymorphonucleated cell migration to the intestinal cell walls, thus preventing initial colonisation by wild strains (Van Immerseel et al., 2005).

In the present study, a killed multi-serotype vaccine was injected into hens after 12 weeks of age to provide humoral protection. Bailey et al. (2007a) administered an aro $A$ attenuated Enteritidis vaccine at 1 and 21 days followed by an autogenous killed trivalent vaccine to 11 and 17 week old broiler breeder parents. Following post-vaccination autologous challenge, the reduction in caecal counts and increase in antibody titre were similar in the study of Bailey et al. (2007ab) and the present study, suggesting the killed vaccine alone is effective.

However, Deguchi et al. (2009) administered an autologous trivalent (Enteritidis, Typhimurium and Infantis) killed vaccine at only 6 weeks of age and was able to show an increased antibody titre and reduced caecal carriage, for challenge (109 $\mathrm{cfu}$ ) with all autologous serovars. The variable results across these studies suggest that the effectiveness of vaccination may vary with the nature and timing of administration of the vaccine. The efficacy of a killed vaccine can be enhanced by using improved adjuvants that may target different parts of the immune system (Barrow 2007).

The modest total colonisation rates in non-vaccinated hens of $33 \%$ and $42 \%$ (Experiment 1 and 2) illustrated that the challenge dose $\left(10^{7} \mathrm{cfu}\right)$ may have been too low or the strains were attenuated. Other studies (Byrd et al., 2003; Babu et al., 2004) showed high rates of colonisation (> 80\%) with high challenge doses of Typhimurium ( $10^{8}$ to $10^{9} \mathrm{cfu}$ and $10^{10} \mathrm{cfu}$ respectively). However, the $10^{7} \mathrm{cfu}$ challenge dose was chosen as this is a more realistic, field-appropriate, natural challenge, than $10^{10} \mathrm{cfu}$.

Numerous studies indicate avian susceptibility to Salmonella is not uniform and many influencing factors exist. The literature suggests that a stable anaerobic microflora, low house density, bacterial interference, breed resistance, antagonism, colonisation resistance, barrier effects, challenge strain virulence, competitive exclusion and passive immunity could all contribute to low challenge rates (Lloyd et al., 1977; Fuller, 1989; Mead and Barrow, 1990; Kottom et al., 1995; Duchet-Suchaux et al., 1997; Nisbet et al., 2000; Quinn et al., 2000; Chambers and Lu, 2002; Kinde et al., 2005). 
The hens used in this study were derived from a field trial situation, stocked at low densities and were healthy, thus decreasing their susceptibility to colonisation to levels less than expected than under the stressful conditions of industry practices. When this vaccine was used under field conditions, over a four year period, the incidence of Typhimurium was reduced in vaccinated flocks with an anti-Typhimurium ELISA titre of > 1000 (Figure 5).

The results summarised in Tables $2.1 \mathrm{~b}$ and 2.1c highlight autologous and heterologous serotype protection conferred by the multivalent vaccine and these trial results were similar to those of Clifton-Hadley et al. (2002) during trial of the first Salenvac ${ }^{\circledR}$ bi-vaccine. The repeatability with $S$. Typhimurium in both trials was expected and heterologous protection was demonstrated with the serogroup B serotype Agona. Protection against heterologous serotypes from serogroup B was also demonstrated by Beal et al. (2006).

The serovars Orion and Zanzibar (serogroup E) were both chosen due to their field prevalence at the time in chicken litter and meat (Davos, 2005). However, these serovars both failed to colonise caeca 21 days after challenge. While detection in flocks may suggest colonisation, such serovars may derive from the environment or feed and be transitory or only capable of minimal colonisation in the birds; still detectable by drag swabs of flocks.

The x-OVO Guildhay Salmonella Typhimurium lipopolysaccharide ELISA was used in this study to measure the immune response to the vaccine, as it was used during development of the first Salenvac killed vaccine (McMullin et al., 1997). The trivaccine contains $1 \times 10^{8} \mathrm{cfu}$ of each of the three serovars added in a ratio of 1:1:1.

The assumption is that the hen develops antibodies to each serovar at titres similar to those determined for S. Typhimurium. Okamura et al. (2007) demonstrated similar Salmonella lipopolysaccharide ELISA antibody titres in hens, vaccinated with a killed bivalent vaccine containing serovars Enteritidis and Typhimurium.

A comparison using the $\mathrm{x}-\mathrm{OVO}$ Guildhay Typhimurium kit and a commercial swine Salmonella (Typhimurium, Infantis and Enteritidis) kit, at a 1:500 dilution with anti-chicken conjugate and substrate added to both kits and read at 550nM showed a 1:0.8 ratio, which was highly significant (Student $t$-test $P<0.0001$ ). While the ratio was not the theorised 1:1 ratio, there was a consistently higher OD observed in the Idexx trivalent kit, which may be attributed to the presence of serogroup $\mathrm{C} 1$ antibodies.

The $S$. Typhimurium ELISA results in experiment 1 and 2 were significantly different (Student $t$-test $P=0.001$ ) between vaccinated and non-vaccinated hens (titre $<460$ ) (Table 4 ) and results from this trial are very similar to the cited trials and therefore protective levels of antibodies have to be present in vaccinated hens caeca (Clifton-Hadley et al., 2002; Beal et al., 2006; Okamura et al. 2007; Deguchi et al. 2009).

As this was a new vaccine an extremely high co-efficient of variance (127\%) was observed in, the commercial field, vaccinated flocks used in Experiment 1 . This may have been due to phase separation of the adjuvant and the killed cells gravity settled to the bottom of the vial. The repeat Experiment (2) the vaccine suspension was vigorously shaken prior to hand vaccination under trial conditions. This resulted in a decreased co-efficient of variation in vaccinated hens to $26 \%$ and a higher percentage positive ( $36 \%>785$ titre).

Prior to Experiment 2 (heterologous challenge), all hens were sourced unvaccinated, then manually vaccinated at 12 and 17 weeks to measure the seroconversion rate. The data 
summarised in Table 5 indicated seroconversion (> 785 titre) which, while slow between the priming dose at 12 weeks of age $(8 \%)$ and the booster at 17 weeks $(18 \%)$, peaked at $43 \%$ by 20 weeks of age. Deguchi et al. (2009) also observed significantly high titre values four weeks post vaccination and McMullin et al. (1997) indicated that a minimum of $30 \%$ of hens positive serologically by 22 weeks of age was required to confer flock immunity (to colonisation by $S$. Enteritidis using Salenvac vaccine and the Guildhay ELISA for $S$. Enteritidis). In the present study, $43 \%$ of hens were seropositive (titre $>785$ ) after 20 weeks, indicating flock immunity.

The Guildhay method requires an initial serum dilution of 1:500 whereas similar work with killed Typhimurium used initial serum dilution of 1:250, 1:400 and 1:400 respectively (Beal et al., 2005; Withanage et al., 2005; Bailey et al., 2007a). The higher initial dilution rate may have greatly reduced the number of ELISA positives in this trial.

In the vaccinated flock challenged with $S$. Typhimurium (Table 2a) the strain was recovered from the caeca of only one hen $(n=11)$ compared to six hens in the non-vaccinated group $(n$ $=12$ ). The vaccination of hens against Salmonella may aid in the decrease of Salmonella numbers house from the caeca, and thus decrease shell contamination, which may, in turn, prevent chick colonisation during hatching.

The amount of IgY transferred to the egg yolk is proportional to maternal serum IgG concentrations (Loeken and Roth, 1983; Al-Natour et al., 2004; Hamal et al., 2006). The transfer of circulating anti-Salmonellae antibody (IgG) into egg yolk (IgY), was demonstrated by Chalghoumi et al. (2008) and Bailey et al. (2007a), after vaccination with serovars Enteritidis and Typhimurium.

Therefore, it is expected that antibodies against the three vaccine strains used in this study would have been transferred to the yolk. In the present study, the detection of serovar Typhimurium antibodies (titre $>785$ ) were measured in $16 \%$ of egg yolks, and $52 \%$ contained no Typhimurium antibody (titre $<460$ ). In addition, $32 \%$ of yolks gave titres that were in the 'suspect' range for the ELISA (460 to 784).

The data suggest maternal transfer of IgY of Typhimurium antibodies from vaccinated hens. The level of detection in this study was $16 \%$ (> 760) or $48 \%(>460)$ and was similar to the $30 \%$ achieved in a previous study (Hamal et al., 2006).

The variable level of titre measured in egg yolk may be an artefact from initial dilution (1:500), as discussed previously, especially when compared to the study of Hassan and Curtiss (1996) egg yolk dilution of 1:100. The titres of anti-Salmonella antibody in this study ranged from 538-1784 and 145-1890 in serum and yolk respectively (at the 95th percentile), indicating that sero-conversion was not uniform among hens.

Therefore, low level of circulating antibody would likely result in transfer of a low level of antibody into the egg yolk. Also, as the eggs were sampled from pens and not individual hens, only broad comparisons could be made. The presence of anti-Typhimurium IgY in egg yolk from vaccinated hens was not observed as increased anti-Typhimurium IgG in their serum of their progeny.

The final experiment (Experiment 3) measured the effects of maternal anti-Salmonella antibodies in day-old chicks, challenged with different doses of $S$. Typhimurium. Reduction 
in colonisation by $S$. Typhimurium is problematic, even in vaccinated chicks. While good reduction has been observed when chicks are challenged with $10^{4} \mathrm{cfu}$, reduction is poor at higher challenge doses ( $10^{6}$ and $10^{8} \mathrm{cfu}$; Nisbet et al., 2000; Clifton-Hadley et al., 2002).

Methner et al. (1999) showed a 0.5-1.5 $\log _{10}$ cfu reduction in carriage in vaccinated chicks challenged with variable populations of $S$. Typhimurium. Bailey, et al. (2007b) showed a 0.5 $\log _{10}$ reduction in day old progeny from vaccinated hens, challenged with $10^{7} \mathrm{cfu}$, which may be due to maternal IgY.

In the present experiment, in vaccinated chicks, a $25 \%$ clearance from caeca was observed in chicks challenged with $10^{4} \mathrm{cfu}$, while no reduction was evident using a $10^{8} \mathrm{cfu}$ challenge (Table 6), indicating a limit to protection by maternal antibodies.

The literature showed conflicting results with respect to maternal antibody protection against Salmonella colonisation; Hassan and Curtiss (1996) showed protection whereas Bailey et al. (2007b) showed no protection. There is a need for more experimental work in this area using standardised ELISA, challenge and measurement techniques.

Regardless of challenge dose, Nisbet et al. (2000) showed a $2 \log _{10}$ reduction in Salmonella establishing in the caeca whereas Clifton-Hadley et al. (2002) suggested that high challenge doses of highly invasive and virulent $S$. Typhimurium may overcome those components of the immune system associated with the systemic phase of infection. Therefore, the $10^{4} \mathrm{cfu}$ challenge is the minimum dosage that will not overwhelm the immune system and still results in colonisation of non-vaccinated controls.

Based on the results of this study, vaccination of all breeder flocks by several Australian commercial broiler growers was introduced as an adjunct to other Salmonella control measures. The effectiveness of this vaccine in the field was tested using routine monitoring data, for blood and drag swabs for weeks 6, 14, 18, 22, 33, 43, 53 for the year prior (2003) to vaccination, during vaccination (2004) and post vaccination (2005). The results showed an overall decrease in flock prevalence from 51\% (2003) to $40 \%$ and $41 \%$ (2004 and 2005 respectively) which, while not statistically significant $\left(\chi^{2} P=>0.05\right)$, was an important reduction. The comprehensive risk assessment produced by the FAO/WHO (2002) stated that "there was a one to one relationship (assuming that everything else remains constant) between percentage change in prevalence to expected risk of illness". The example cited by the FAO/WHO (2002) stated that if prevalence reduced from $20 \%$ to $10 \%$, this would result in a similar $50 \%$ reduction of risk in illness per serving.

The reduction in flock prevalence was noticed across all flock ages (Figure 3) with a reduction in chick ( $<12$ woa) prevalence, which may be attributed to maternal tri-vaccine antibody (Hassan and Curtiss, 1996). The increase in Salmonella prevalence during weeks 13 to 22 may be due to the hen sexual maturity, which may be associated with a situation akin to the peri-parturient relaxation of resistance (Kelly, 1973) seen in mammals.

This condition is contributory to susceptibility of sheep to parasite infection after birth and has been attributed to the release of prolactin (Kelly, 1973). Hens also produce prolactin, initiating broodiness, which may limit early egg production and may increase their susceptibility to Salmonella colonisation (Leboucher et al., 1990; Talbot et al., 1991; March, et al., 1994; Berry, 2003). 
The increase in flock prevalence of Salmonellae in that age bracket (13 to 22 weeks) may also be due to the introduction of males from other rearing houses. These males were not vaccinated and may have been a source of Salmonella.

There was a decrease in Salmonella prevalence post-vaccination, (2004-2005) across all age groups, for serogroups $\mathrm{B}$ and $\mathrm{C}$ but not for serogorup $\mathrm{E}$ (Figure 3 and Table 7). The flock horizontal data are very similar to the observations noticed in the trial (Table 2) and support the hypothesis that serogroup $\mathrm{E}$ is transitory and does not persistently colonise the avian intestinal tract.

There was also a change in Salmonella serovar profile (Table 7), with 13 serovars in 2003 accounting for $97 \%$ of all flock isolates. When these same serovars were tracked through the vaccination years (2004 to 2005) they accounted for only $88.6 \%$ and $71.9 \%$ respectively. The biggest change in prevalence was observed in the non-vaccine serovars Senftenberg (serogroup E4) from $0.6 \%$ in 2003 to $4.7 \%$ in 2005 and subsp. 1 ser rough:r: 1,5 from $0.6 \%$ to $14.6 \%$ for the same time period (Figure 3 and Table 7).

The serovar changes observed may have been introduction through feed, litter, vermin, and equipment (FAO/WHO, 2002; Arsenault et al., 2007). The presence of this rough:r:1, 5 serovar has identical flagellar antigens to Infantis, suggesting these isolates are variants of that serovar. The term "rough" means that this Salmonella is devoid of somatic antigens (lipopolysaccharide). However, its flagellar antigenic structure is very similar to that of serovar Infantis (Davos, personal communication).

According to the complete Le Minor-White-Kauffman scheme there are 11 other serovars that have the same flagellar structure: Bradford (serogroup [B]); Czernyring [054]; Abertbanju [V]; Lubumbashi [S]; Hindmarsh $\left[\mathrm{C}_{2}-\mathrm{C}_{3}\right]$; Linde $[\mathrm{P}]$; Jamaica $\left[\mathrm{D}_{1}\right]$; Ughelli $\left[\mathrm{E}_{1}\right]$; Senegal [F]; Tennenlohe [K] and Gege [N] (Grimont and Weill, 2007). However, none of these serovars have been isolated in Australia (Davos, 2008) thus supporting the initial hypothesis that this rough strain is a variant of Infantis.

The flock seroconversion of the Typhimurium component was measured and reported in Figure 4. The annual (2004 and 2005) flock positive (> 785) titre rates (flock immunity) were $28 \%$ and $27 \%$ respectively, with peak rates recorded between 13 and 22 woa. These figures were less than the trial figure of $43 \%$ at 20 woa and slightly lower than the $30 \%$ seroconversion described by McMullin et al. (1997). This may be due to difficultly in hand vaccinating thousands of hens per day (shown by the wide $95 \%$ confidence range) and the stress placed upon the hen which may act as an immunosuppressant and compromise seroconversion (Shini et al., 2010).

The data summarised in Figure 5 suggest that a high average titre ( $>1000$ mean) may aid in reduced shedding of serovar Typhimurium within the flock. This may be due to the increased production of IgY and IgA within the gut of the hen (Bailey et al., 2007a). The mean titre of 1000 was chosen as its S/P ratio was 0.35 which was 0.1 larger than the cut-off positive S/P ratio of 0.25 . The cut off age of 25 weeks was chosen as that is approximately the age when the hens are in full fertile egg production.

An interesting observation was seen on a day old to death (Aug to Jun) farm with six houses (flocks) on which all were colonised with Typhimurium prior to vaccination. The flock in the fourth house had a high mean titre (2566 and $75 \%$ flock immunity) and was clear of 
Typhimurium colonisation at 23, 33 and 43 woa (no 53 woa swabs taken) whereas the adjoining flocks in houses three and five, with low titres (266 and 786 respectively), were still positive for Typhimurium after 33 and 43 weeks.

In another State, a four-house day old to death (Oct to Sep) complex had the first house with a high mean titre (1246) and was negative for Typhimurium after 25 weeks whereas the adjoining three houses with low titres $(426,828$ and 533) were positive after 25 weeks. More controlled research is required to understand the factors contributing to clearance.

As these flocks were on the same farm and the adjoining houses were positive, then it may be safe to assume that the feed and water were Salmonella free and biosecurity prevented cross-contamination. However, both of these farms had relatively young flocks over the Australian summer (Nov to Feb). These poultry farms have curtained sides, and the presence of flies is very high. Flies are known carriers of Salmonella (Wales et al., 2010) and could continuously reinfect the flocks, therefore limiting the effectiveness of biosercurity in preventing Salmonella colonisation and spread.

Another possible explanation is that the isolation of Salmonella using a drag swab may favour the dominant serovar within the flock and the sub-dominant serovars may be masked or have a lower probability of detection. However, this error should be consistent throughout the farm and a reduced number of Typhimurium would also mean a reduced risk as mentioned previously.

The two most consistent observations are that both these flocks, in different locations and States, had high (> 1000) Typhimurium titres; as Occam's (or Ockham's) Razor states, "with all things being equal the simplest solution is often the correct one" (Anonymous, 2010). Therefore high titre and flock immunity is very important in clearance of Typhimurium.

One of the problems associated with horizontal field trials is the absence of contemporary controls. Therefore, assumptions are made that all growing conditions, feed, water supply and management are the same (constant variable), with vaccination (controlled variable) and Salmonella exposure (uncontrolled variable) the measured variables. Unfortunately, when using commercial broiler flocks, in real world situations, as the time frame increases so too does the possibility that flock management practices may change due to flock illness or economic necessities thus altering crucial parameters. Therefore, any conclusions made from historical data need to be guarded and very general.

In conclusion, the vaccination of $\mathrm{Cobb}^{\mathrm{TM}}$ breeders with an autologous vaccine demonstrated statistically significant reduction in serogroup B and C colonisation following challenge at $10^{7} \mathrm{cfu}$ per bird. Seroconversion of the vaccinated hens, as well as maternal transfer of antibodies to the egg yolk, was shown. Challenge $\left(10^{4} \mathrm{cfu}\right.$ per bird) trials with day-old chicks demonstrated a significant difference in colonisation of progeny from vaccinated versus non-vaccinated parents. The horizontal analysis over a three year period (2003 to 2005) showed that the number of colonised flocks decreased by $10 \%$ following vaccination and, if the vaccine titre mean was greater than 1000 the likelihood of persistent colonisation was reduced by 17 times.

\subsection{Prophylaxis trial}

It is well documented that young ( $<3$ woa) chicks lack a mature gut flora and immune system and therefore are more susceptible to Salmonella colonisation (Nurmi and Ratala 
1973; Martin et al., 2000;). The transfer of maternal antibodies from the yolk to the chick may prevent colonisation of chicks by Salmonella (Hassan et al., 1996).

The data summarised in Table 9 shows that maternal antibodies for Salmonella Typhimurium are transferred from hen serum to the egg yolk and these antibodies can be chemically extracted (Staak et al., 2001). However, there is a large variation in these data (15 $\%$ to $80 \%$ ) in terms of the number of eggs that were positive for $S$. Typhimurium antibodies. This may be due to the level of seroconversion and the subsequent production of circulating antibody within the donor hen. Hamal et al. (2006) showed a relationship between plasma antibody levels and transfer into the yolk. These authors also noticed a farm difference in the serum antibody levels to the same vaccine, though, the serum to egg transfer rate was similar in both farms.

The data in Table 9 shows that hens from farm 3, with a high flock mean Typhimurium serum (ELISA titre of 2104), also had $80 \%$ of their yolks positive. These yolks, when chemically extracted, had a high crude extract mean anti-Typhimurium antibody titre (ELISA titre of 6900). The extract titres were higher than the initial serum level and similar observations have been made in numerous studies (Rose et al., 1974; Kariyawasam et al., 2004; Malik et al., 2006; Yegani and Korver, 2010).

The farm (1) that had the lowest levels of Typhimurium IgY was further investigated by performing repeats $(n=8)$ of each individual yolk tested (Figure 8$)$. These data (Figure 8 ) showed that there was a lot of variation within the egg yolk as signified by the large $95 \%$ confidence limits error bars. This may be due to either mechanical error, such as difficultly in accurately pipetting $100 \mu \mathrm{l}$ of highly viscous egg yolk, or that the amount of $S$. Typhimurium IgY present was so low that it reduced the probability of detection. An alternative method would be to weigh approximately $100 \mu \mathrm{g}$ of egg yolk instead of pipetting.

The yields of crude IgY which was chemically extracted (Staak et al., 2001) from egg yolks was higher ( 26 to $32 \mathrm{mg} / \mathrm{g}$ ) than expected (20 to $25 \mathrm{mg} / \mathrm{g}$ ) from another study employing the same method (Rose and Orlans, 1981). This higher yield may be due to the extraction of some low molecular weight proteins. This observation could be further investigated through electrophoretic analysis of the extracts to determine the size of the impurities.

In the previous Section (4.1) it was shown that maternal antibody to $S$. Typhimurium can confer some protection to chicks challenged with low levels $\left(10^{4}\right)$ of $S$. Typhimurium. This led to the hypothesis that feeding day old chicks rations supplemented with antiTyphimurium IgY may provide passive immunity. This hypothesis was based upon the review by Schade et al. (2005), which described many examples of transfer of antibody against specific pathogens from hyperimmunized hens into the egg. In recent years, there have been many trials that tested the efficacy of such antibodies against Salmonella in vitro (Lee et al., 2002; Chalghoumi et al., 2009a) and in vivo (Gurtler et al., 2004; Rahimi et al., 2007; Chalghoumi et al., 2009b).

In the present trial the effects of IgY supplemented feeds on the growth rate, as well as protection from colonisation upon challenge with $10^{4}$ and $10^{5} \mathrm{cfu}$ of $S$. Typhimurium, were evaluated; the challenge dose was based upon populations likely to be encountered naturally. The initial part of the trial was to observe and measure whether the chicks would consume the treated feeds and the effects of these on weight gain. 
One of the concerns was the salt content in the crude yolk extract may make the feed unpalatable or that other antibodies in the crude yolk extract may interact adversely within the gastrointestinal tract thus affecting feed conversion. The results for this aspect of the trial are summarised in Figure 9 and show that there was no significant (Student $t$-test $P=0.56$ ) difference in weight gain between the treated and control chicks, as shown by Kassaify and Mine (2004) in field trials.

Chicks consumed a standard dose of $1.42 \mathrm{~g}$ antibody extract/chick/day. This dosage was calculated from Anonymous (2007) and was based upon 3 \% (Gurtler et al., 2004) of daily intake at 11 days (trial midpoint) of age.

The titre of the Typhimurium IgY in the treated feeds was measured daily (Figure 10) and showed that there was a high degree of variation in dosage. The feed treated with dried anti-Typhimurium egg yolk (dT-IgY), resuspended in crude S. Typhimurium containing IgY extract, and had the most consistent titre. The dried feed supplemented with $3 \%$ dried egg yolk was the most variable. This may be due to the difficulty of evenly distributing the dried egg yolk throughout the ration; the titres in reconstituted (wet) feeds were much more consistent.

Finally, after 15 days of age, the chicks were euthanized and their caeca removed for enumeration of $S$. Typhimurium (Figure 11). The results showed, regardless of the treatment and challenge level, that there was no significant difference (Student $t$-test $P=0.65$ ) between treatment and control groups.

The work performed by Kassaify and Mine (2004) measured the effects of egg yolk powder at $2.5 \%, 5 \%, 7.5 \%$ and $10 \% \mathrm{w}: \mathrm{w}$ and showed that Salmonella Typhimurium colonisation in poultry was eliminated at only the $10 \% \mathrm{w}$ : w concentration. The authors suggested that egg yolk containing anti-infection and adhesive factors, which may agglutinate the pathogen, stimulates the immune system or factors compete for adhesion sites (Kassaify and Mine, 2004).

Based on this result the concentration of egg yolk in the current trial, at $3 \%$, may have been too low and an insufficient amount of egg yolk containing anti-Typhimurium IgY reached the caeca. The former is supported by the work of Chalghoumi et al. (2009b) who also showed no significant caecal reduction in four-day-old chicks challenged with $10^{6} \mathrm{cfu}$ Typhimurium or Enteritidis fed 1 to $5 \%$ (w:w) freeze dried egg yolk containing antiSalmonella IgY.

The $3 \%$ dose rate was based on the work of Gurtler et al. (2004), which demonstrated a significant reduction in $S$. Enteritidis contamination of eggs from hens that were challenged with high levels of Enteritidis $\left(10^{8}\right.$ and $\left.10^{9}\right)$. This challenge rate was not used in the present study as it was not considered to represent a natural infective dose.

An alternate delivery method, IgY administered for 28 days in drinking water, led to a reduction in caecal colonisation of Enteritidis, administered at $10^{6} \mathrm{cfu}$, to $0.27 \log _{10}$ compared to controls, at $3.98 \log _{10} / g$ (Rahimi et al., (2007). This method may be preferable to adding IgY directly into feed, as the water lines can be set to dose at a specific concentration. In standard Australian veterinary practice antimicrobials are added into water to treat disease and in feed for prophylactic treatment. 
The initial concentration of egg yolk containing IgY may be critical as these orallyadministered antibodies, like any other protein molecule, are susceptible to denaturation by the acidic $\mathrm{pH}$ of the proventriculus and gizzard and degradation by proteases (Yegani and Korver, 2010). However, there are reports in the literature that suggest that the IgY $\mathrm{F}_{\mathrm{ab}}$ fragments maintain their ability to bind antigen, even after exposure to pepsin and trypsin and at pH 4.0 (Shimizu et al., 1988; Carlander et al., 2000; Gurtler et al., 2004). Therefore, there may be a percentage of the yolk containing IgY digested with only a limited portion still being active post-digestion.

These antibodies, post-digestion, would decline in immunological activity and concentration as they progressed from the proximal to distal regions of the intestine, due to viscosity and passage rate, but remain detectable in the caecum and therefore reducing the probability of antibody encountering and binding the antigen (Reilly et al., 1997; Wilkie et al., 2006; Yegani and Korver, 2010). These factors may influence the ability of IgY to prevent colonisation by specific pathogens in the lower parts of the intestinal tract. It may be possible to develop a protease-resistant oral dosage form of IgY in order to increase the fraction of immunoreactive antibody delivered locally in the gastrointestinal tract (Reilly et al., 1997).

The easiest method to ensure that effective concentration of $\operatorname{IgY}$ reaches the caeca is to ensure that the initial concentration of dried egg yolk is high enough to deliver a dosage of antibody inhibitory toward Salmonella into the caeca. The literature reviewed currently suggested that $10 \%(\mathrm{w}: \mathrm{w})$ would be the optimum dosage.

In conclusion, this study demonstrated the successful chemical extraction of Typhimurium IgY transferred from serum to egg yolk for three different flocks. However, when yolk containing Typhimurium IgY was added to dry chick feed at $3 \%(w: w)$ and fed prophylactically to dayold chicks there was no protection observed when these chicks were challenged with $S$. Typhimurium $\left(10^{5} \mathrm{cfu} / \mathrm{mL}\right)$. This was possibly due to the feed dosage being too low or an inability of the orally administered antibodies to reach the site of activity required.

\section{Conclusion}

The autologus Salmonella tri-vaccine was shown to convey protection from colonisation of autologous and heterologous Salmonella challenge in the hen and to convey maternal antibodies to progeny. These maternal antibodies helped protect day-old chicks from colonisation after low-level challenge with Salmonella Typhimurium (at an age of 14 days). However, when these maternal antibodies were extracted from vaccinated hens' eggs and fed to non-vaccinated day old chicks for prophylaxis there was no difference in caecal colonisation rates between treated and untreated groups.

Reduction of the prevalence of Salmonella in flocks will benefit society by a potential reduction in human foodborne illness, as highlighted by a FAO/WHO (2002) risk assessment, which showed that for every $50 \%$ reduction in prevalence there is also a $50 \%$ reduction in risk.

\section{References}

ABARE (Australian Bureau of Agricultural and Resource Economics) (2008), Australian Commodity Statistics, Canberra, ACT. Australia. 
Al-Natour, M. Q., Ward, L. A., Saif, Y. M., Stewart, B. and Keck L. D. (2004). Effect of different levels of maternally derived antibodies on protection against infectious bursal disease virus. Avian Dis. 48, 177-182.

Animal Research Act 1985. New South Wales Consolidated Regulations, Australia. www.austlii.edu.au/au/legis/nsw/consol_act/ara1985134 \{accessed 26/5/07\}.

Animal Research Regulation 2005. New South Wales Consolidated Regulations, Australia. www. austlii.edu.au/au/legis/nsw/consol_reg/arr2005225 \{accessed 26/5/07\}.

Anonymous (1999). Submission to the inquiry into primary producer access to gene technology. Australian Academy of Science. www.science.org.au \{accessed 18/1/11\}.

Anonymous (2004). The use of vaccines for the control of Salmonella in poultry. The EFSA Journal 114, 1-74.

Anonymous (2007). Cobb 500 Broiler Growth \&and Nutrition Supplement Metric Version. Cobb-Vantress Inc Arkansas.

Anonymous (2010). www.Merrian-Webster.com/dictionary/occam'srazor $\quad$ accessed $23 / 3 / 10\}$

Arsenault, J., Letellier, A., Quessy, S., Normand, V. and Boulianne, M. (2007). Prevalence and risk factors for Salmonella spp. and Campylobacter spp. caecal colonisation in broiler chicken and turkey flocks slaughtered in Quebec, Canada. Prev. Vet. Med. $81,250-264$.

Arzey, G., (2005). Guidelines - Joint NSW/Victoria Salmonella Enteritidis monitoring and accreditation program. Elizabeth Macarthur Agricultural Institute, Menangle NSW Department of Primary Industries, Australia.

AS/NZS 5013.11.1 (Australian/New Zealand Standard) (2004). Microbiology of food and animal feeding stuffs-Preparation of test samples, initial suspension and decimal dilutions for microbiological examination-General rules for the preparation of the initial suspension and decimal dilutions. Standards Australia/Standards New Zealand.

Babu, U., Scott, M., Myers, M.J., Okamura, M., Gaines, D., Yancy, H.F., Lillehoj, H., Heckert R.A. and Raybourne R.B. (2003). Effects of live attenuated and killed Salmonella vaccine on T-lymphocyte mediated immunity in laying hen. Vet Immunol Immunopathol, 91, 39-44.

Bailey, J.S., Rolón, A., Hofacre, C.L., Holt, P.S., Wilson, J.L., Cosby, D.E., Richardson, L.J. and Cox, N.A. (2007b). Resistance to challenge of breeders and their progeny with and without competitive exclusion treatment to Salmonella vaccination programs in broiler breeders. Internat. J. Poult. Sci 6, 386-392.

Bailey, J.S., Rolón, A., Holt, P.S., Hofacre, C.L., Wilson, J.L., Cosby, D.E., Richardson, L.J. and Cox, N.A. (2007a) Humoral and mucosal-humoral immune response to a Salmonella vaccination program in broiler breeders. Internat. J. Poult. Sci 6, 172-181.

Barrow, P.A. (2007). Salmonella infections: Immune and non-immune protection with vaccines. Avian Pathol. 36, 1-13.

Barrow, P.A., Huggins, M.B. and Lovell, M.A., (1994). Host specificity of Salmonella infection in chickens and mice is expressed in vivo primarily at the level of the reticuloendothelial system. Infect. and Immun. 62, 4602-4610.

Beal, R.K. and Smith, A.L. (2007). Antibody response to Salmonella: its induction and role in protection against avian enteric salmonellosis. Exp. Rev. Anti-infect. Ther., 5, 873-881. 
Beal, R.K., Powers, C., Wigley, P., Barrow, P.A., Kaiser, P. and Smith, A.L. (2005). A strong antigen specific T-cell response is associated with age and genetically dependent resistance to avian enteric salmonellosis. Infect. Immun. Nov, 7509-7516.

Beal, R.K., Wigley, P., Powers, C., Barrow, P.A., and Smith, A.L. (2006). Cross-reactive cellular and humoral immune responses to Salmonella enterica serovars Typhimurium and Enteritidis are associated with protection to heterologous rechallenge. Vet Immunol Immunopathol 15, 84-93.

Berry, W.D. (2003). The physiology of induced molting. Poult. Sci. 82, 971-980.

Braden, C.R. (2006). Salmonella enterica, serovar Enteritidis and eggs: a national epidemic in the United States. Clin. Infect. Dis, 43, 512-517.

Buzby, J.C. and Farah, H.A. (2006). Chicken consumption continues long run rise. Amber Waves 4,5 .

Byrd, J.A., Anderson R.C., Callaway T.R., Moore R.W., Knape K.D., Kubena L.F., Ziprin R.L. and Nisbet D.J. (2003). Effect of experimental chlorate product administration in the drinking water on Salmonella Typhimurium contamination of broilers. Poult. Sci. 82, 1403-1406.

Callaway, T.R., Edrington, T.S., Anderson, R.C., Byrd J.A. and Nisbet, D.J. (2008). Gastrointestinal microbial ecology and the safety of our food supply as related to Salmonella. J. Anim. Sci. 86, E163-E172.

Carlander, D., Kollberg, H., Wejaker, P. E., and Larsson, A. (2000). Peroral immunotherapy with yolk antibodies for the prevention and treatment of enteric infections. Immuno. Rrev., 21, 1-6. Review.

Chalghoumi, R., Marcq, C., Thewis, A., Portetelle, D. and Beckers, Y. (2009b). Effects of feed supplemented with specific hen egg yolk antibody (immunoglobin Y) on Salmonella species caecal colonization and growth performances of challenged broiler chickens. Poult. Sci. 88, 2081-2092.

Chalghoumi, R., Thewis, A., Beckers, Y., Marcq, C., Portetelle, D. and Schneider, Y.-J. (2009a). Adhesion and growth inhibitory effect of chicken egg yolk antibody (IgY) on Salmonella enterica serovars Enteritidis and Typhimurium in vitro. Foodborne Pathog. Dis. 6, 593-604.

Chalghoumi, R., Thewis, A., Portetelle, D. and Beckers Y. (2008). Production of hen egg yolk immunoglobulins simultaneously directed against Salmonella Enteritidis and Salmonella Typhimurium in the same egg yolk. Poult. Sci. 87, 32-40.

Chambers, J.R. and Lu, X. (2002). Probiotics and maternal vaccination for Salmonella control in broiler chickens. J. Appl. Poult. Res. 11, 320-327.

Clifton-Hadley, F.A., Breslin, M., Venables, L.M., Sprigings, K.A., Cooles, S.W., Houghton, S. and Woodward, M.J. (2002). A laboratory study of an inactivated bivalent iron restricted Salmonella enterica serovars Enteritidis and Typhimurium dual vaccine against Typhimurium challenge in chickens. Vet. Microbiol. 89, 167-179.

Codex Alimentarius Commission (2004). Discussion paper on risk management strategies for Salmonella spp. in Poultry. Joint FAO/WHO food Standard Program Codex committee on food hygiene thirty-sixth session, Washinton DC, United States of America, 29 March - 3 April 2004.

Cox, J.M and Pavic, A (2010). Advances in enteropathogen control in poultry production. J. Appl. Microbiol. 109, 25-34. 
Davos, D. (2005) (ed). Australian Salmonella Reference Centre 2004 Annual Report. Institute of Medical and Veterinary Science. Adelaide. South Australia.

Davos, D. (2007) (ed) Australian Salmonella Reference centre 2006 annual report. Institute of Medical and Veterinary Science. Adelaide. South Australia.

Davos, D. (2008) (ed). Australian Salmonella Reference Centre 2007 Annual Report. Institute of Medical and Veterinary Science. Adelaide. South Australia.

Deguchi, K., Yokoyama, E., Honda, T., and Mizuno, K. (2009). Efficacy of a novel trivalent inactivated vaccine against the shedding of Salmonella in chicken challenge model. Avain. Dis. 53, 281-286.

Duchet-Suchaux, M., Mompart, F., Berthelot, F., Beaumont, C., Lechopier, P., and Pardon, P. (1997). Differences in frequency, level, and duration of caecal carriage between four outbred chicken lines infected orally with Salmonella Enteritidis. Avain Dis., 41, 559567.

EFSA (European Food Safety Authority) (2007). The Community summary report on trends and sources of zoonoses, zoonotic agents, antimicrobial resistance and foodborne outbreaks in the European Union in 2006. EFSA J. 130, 1-352.

FAO/WHO. (Food and Agriculture Organisation of the United Nation and the World Health Organisation) (2002). Risk assessments of Salmonella in eggs and broiler chickens. In Microbiological risk assessment series 2. World Health Organization / Food and Agriculture Organization of the United Nations. ftp:/ /ftp.fao.org/docrep/fao/005/y4392e/y4392e00.pdf \{accessed 12/01/09\}.

Foley, S.L. and Lynn, A.M. (2008). Food animal-associated Salmonella challenges: pathogenicity and antimicrobial resistance. J. Anim Sci. 86, E173-187.

Franco, D.A. (2005). A survey of Salmonella serovars and most probable numbers in rendered-animal-protein meals: inferences for animal and human health. J. Environ. Health, 67, 18-22.

Fuller R. (1989). Probiotics in man and animals. J. Appl Bacteriol, 66, 365-378.

Giannella, R.A. (1996). Salmonella, in Medical Microbiology, 4th edition, eds Baron, S., Univesity of Texas Press.

Grimont, P.A.D. and Weill F-X. (2007). Antigenic formulae of Salmonella serovars. WHO Collaborating Centre for Reference and Research on Salmonella.

http://www.pasteur.fr/sante/clre/cadrecnr/salmoms-index.html \{accessed $12 / 11 / 07\}$.

Gurtler, M., Methner, U., Kobilke, H. and Fehlhaber, K. (2004). Effect of orally administered egg yolk antibodies on Salmonella enteritidis contamination of hen's eggs. J. Vet. Med. B. 51, 129-134.

Gurtler, M., Methner, U., Kobilke, H. and Fehlhaber, K. (2004). Effect of orally administered egg yolk antibodies on Salmonella enteritidis contamination of hen's eggs. J. Vet. Med. B. 51, 129-134.

Hamal, K.R., Burgess, S.C., Pevzner, I.Y. and Erf, G.F. (2006). Maternal Antibody Transfer from Dams to Their Egg Yolks, Egg Whites, and Chicks in Meat Lines of Chickens Poult Sci 85, 1364-1372.

Hancock, D.D., Blodgett, D. and Gay, C.C., (1988). The collection and submission of samples for laboratory testing. Vet. Clin. N. Amer: Food Animal. Pract. 4, 33-59. 
Hassan, J.O. and Curtiss, R. (1ll) (1996). Effect of vaccination of hens with an avirulent stain of Salmonella Typhimurium on immunity of progeny challenged with wild-type Salmonella strains. Infect. Immun. 64, 938-944.

ISO 6579:2002. Microbiology of food and animal feeding stuffs - Horizontal method for the detection of Salmonella spp. International Organization for Standardization, Geneva, Switzerland.

Jay, S., Davos, D., Dundas, M., Frankish, E., and Lightfoot, D. (2003). Salmonella. In Foodborne microorganisms of public health significance. Hocking, A.D. (ed). $6^{\text {th }}$ edition, Australian Insitute of Food Science and Technology Incorporated NSW Branch, Food Microbiology Group. Southwood Press Pty Ltd, NSW Aust. 207-267

Kariyawasam, S., Wilkie, B.N. and Gyles, C.L. (2004). Resistance of broiler chickens to Escherichia coli respiratory tract infection induced by passively transferred egg-yolk antibodies. Vet. Microbiol. 98, 273-284.

Kassaify, Z.G., and Mine, Y. (2004). Nonimmunized egg yolk powder can suppress the colonization of Salmonella Typhimurium, Escherichia coli O157:H7, and Campylobacter jejuni in laying hens. Poult. Sci. 83, 1497-1506.

Kelly, J.D. (1973). Immunity and epidemiology of helminthiasis in grazing animals. New Zeal. Vet. J. 21, 183-194.

Kinde H., Castellan, D.M., Kerr, D., Campbell, J., Breitmeyer, R. and Ardans, A., (2005). Longitudinal monitoring of two commercial layer flocks and their environments for Salmonella enterica Serovar Enteritidis and other Salmonellae. Avian Dis. 49, 189194.

Kottom, T.J., Nolan, L.K. and Brown J. (1995). Invasion of Caco-2 cells by Salmonella Typhimurium (Copenhagan) isolates from healthy and sick chickens. Avian Dis 39, 867-872.

Kowalczyk, Daiss, J., Halpern, J. and Roth, T.F. (1985). Quantitation of maternal-fetal IgG transport in the chicken. Immuno. 54, 755-762.

Leboucher, G., Richard-Yris, M.A., Williams, J. and Chadwick, A. (1990). Incubation and maternal behaviour in domestic hens: influence of the presence of chicks on circulating luteinising hormone, prolactin and oestradiol and on behaviour. $\mathrm{Br}$. Poult. Sci. 31, 851-862.

Lee, E.N., Sunwoo, H.H., Menninen, K. and Sim, J. S. (2002). In Vitro Studies of Chicken Egg Yolk Antibody (IgY) against Salmonella Enteritidis and Salmonella Typhimurium. Poult. Sci. 81, 632-641.

Lloyd, A.B., Cumming, R.B. and Kent R.D. (1977). Prevention of Salmonella Typhimurium infection in poultry by pre-treatment of chickens and poults with intestinal extracts. Austral. Vet. J. 53, 82-87.

Loeken, M.R. and Roth T. F. (1983). Analysis of maternal IgG subpopulations which are transported into the chicken oocyte. Immuno. 49, 21-28.

Lutful Kabir, S.M. (2010). Avian Colibacillosis and Salmonellosis: A Closer Look at Epidemiology, Pathogenesis, Diagnosis, Control and Public Health Concerns. Int. J. Environ. Res. Public Health, 7, 89-114.

Malik, M.W., Ayub, N. and Qureshi, I.Z. (2006). Passive immunization using purified IgYs against infectious bursal disease of chickens in Pakistan. J. Vet. Sci 7, 43-46.

Marangon, S. and Busani, L. (2007). The use of vaccination in poultry production. Rev. Sci. Tech. 26, 265-274. 
March, J.B., Sharp, P.J., Wilson, P.W. and Sang, H.M. (1994). Effect of active immunization against recombinant-derived chicken prolactin fusion protein on the onset of broodiness and photoinduced egg laying in bantam hens. J. Reprod. Fertil. 101, 227233.

Martin, C., Dunlap, E., Caldwell, S. and Barnhart, E., (2000). Drinking water delivery of a defined competitive exclusion culture (pre-empt) in 1 day old broiler chicks. J. Appl. Poultry Res. 9, 88-91.

McMullin, P.F., Gooderham, K.R. and Hayes G. (1997). A commercial Salmonella Enteritidis ELISA test: results arising for its use in monitoring for infection and response to an inactivated vaccine. Presented at the World Veterinary Poultry Association Congress, Budapest. http://www.poultry-health.com/library/wvpasens.htm \{accessed 03/12/2003\}

Mead, G.C., and Barrow, P.A. (1990). Salmonella control in poultry by competitive exclusion or immunisation., Let. Appl. Microbiol. 10, 221-227.

Martin, S.W., Meek, A.W., and Willeberg, P. (1988). Veterinary Epidemiology: Principles and Methods. Iowa State University Press, Ames. p45.

Methner, U., Barrow, P.A., Berndt, A. and Steinbach, G. (1999). Combination of vaccination and competitive exclusion to prevent Salmonella colonisation in chickens: experimental studies. Intern. J. Food Microbiol. 49, 35-42.

NHMRC (National Health and Medical Research Council) (2008). Guidelines to promote the wellness of animals used for scientific purposes. The assessment and alleviation of pain and distress in research animals. NHMRC Canberra, Australia.

NHMRC/ARC (National Health and Medical Research Council, Australian Research Council and Universities Australia) (2007). Australian code for the responsible conduct of research. . NHMRC Canberra, Australia.

Nisbet, D.J., Anderson, R.C., Corrier, D.E., Harvey, R.B. and Stanker, L.H. (2000). Modeling the survivability of Salmonella Typhimurium in chicken cecae using an anerobic continous-culture of chicken cecal bacteria. Microbial. Eco. Health Dis. 12, 42-47.

Nurmi, E and Ratala, M., (1973). New aspects of Salmonella infection in broiler production. Nat. 241, 210-211.

Okamura, M., Tachizaki, H., Kudo, T., Kiluchi, S., Suzuki, A., and Nakamura, M. (2007). Comparative evaluation of a bivalent killed Salmonella vaccine to prevent egg contamination with Salmonella enterica serovars Enteritidis, Typhimurium, and Gallinarum biovar Pullorum, using 4 different challenge models. Vacc 25, 48374844 .

Pavic, A., Groves, P.J., Bailey, G., and Cox, J.M. (2010). A validated miniaturized MPN method, based on ISO 6579:2002, for the enumeration of Salmonella from poultry matrices. J. Appl. Microbiol., 109, 25-34

Petrie, A. and Watson, P., (1999). Statistics for veterinary and animal science. Blackwell Publishing. Oxford, UK.

Quinn, P.J., Carter, M.E., Markey, B. and Carter G.R. (2000). Enterobacteriaceae in Clinical Veterinary Microbiology (pp209-237). Mosby International Limited of Harcourt Publishers Limited, Spain.

Rahimi, S., Shiraz, Z. M., Salehi, T. Z., Torshizi, M. A. K. and Grimes, J. L. (2007). Prevention of Salmonella infection in poultry by specific egg-derived antibody. Int. J. Poult. Sci. 6, 230-235. 
Reilly, R.M., Domingo, R. and Sandhu, J. (1997). Oral delivery of antibodies. Future pharmacokinetic trends. Clin. Pharmaco. 32, 313-323.

Rose, M. E. and Orlans, E. (1981). Immunoglobulins in the egg, embryo and young chick. Dev. Comp. Immuno. 5, 15-20.

Rose, M.E., Orlans, E. and Buttress, N. (1974). Immunoglobulin classes on the hen's egg: their segregation in yolk and white. Eur.o J. Immuno 4, 521-523.

Schade, R. Calzado, E.G., Sarmiento, R., Chacana, P.A., Porankiewicz-Asplund, J., and Terzolo, H.R. (2005). Chicken egg yolk antibodies (IgY-technology): a review of progress in production and use in research and human and veterinary medicine. Altern. Lab. Anim. 33, 129-154.

Shimizu, M., Fitzsimmons, R. and Nakai, S. (1988). Anti-E. coli Immunoglobulin Y isolated from egg yolk of immunized chickens as a potential food ingredient. J. Food Sci. 53, 1360-1366.

Shini, S., Huff, G.R., Shini, A. and Kaiser, P. (2010). Exploration of cytokine and chemokine gene profiles in chicken peripheral leukocytes. Poult. Sci. 89, 841-851.

Smith T. (2003). A focus on Salmonella, Food Science Research Information Office, www.nal.usda.gov/fsrio/research/fsheet/fsheet10.htm\#class.

Smith, H.W (1956) The use of live vaccines in experimental Salmonella gallinarum infection in chickens with observations on their interference effect. J. Hyg. Camb. 54, 419-432.

Staak, C., Schwarzkopf, C., Behn, I., Hommel, U., Hlinak, A., Schade, R. and Erhard, M. (2001). Isolation if IgY from yolk. In Chicken egg yolk antibodies, production and application, IgY-technology. Schade, R., Behn, I., Erhard, M., Hlinak, A., Staak, C. (Eds). Springer-Verlag Berlin, Heidelberg, New York. 78-84.

StatSoft (2001) Statistica Version 6. www.statsoft.com.

Talbot, R.T., Hanks, M.C., Sterling, R.J., Sang, H.M. and Sharp, P.J. (1991). Pituitary prolactin messenger ribonucleic acid levels in incubating and laying hens: effects of manipulating plasma levels of vasoactive intestinal polypeptide. Endocrinol. 129, 496-502.

Thrusfield M (2005). Observation. in Veterinary Epidemiology 3rd edition (pp 279) Blackwell Publishing.

U.S-FDA (United.States of America Food and Drug Administration) (2006) Most probable number from serial dilutions. In Bacterial Analytical Manual online Appendix 2. United States Food and Drug Administration, Center of Food Safety and Applied Nutrition, Department of Health and Human Services. http://www.cfsan.fda.gov/ ebam/bam-a2.html [accessed 3/3/08].

Van den Bosch, G. (2003). Vaccination versus treatment: how Europe is tackling the eradication of Salmonella. Asian Poult. Mag. July, 1-3.

Van Immerseel, F., Methner, U., Rychlik, I., Nagy, B., Velge, P., Martin, G., Foster, N., Ducatelle, R. and Barrow P.A. (2005). Vaccination and early protection against nonhost-specific Salmonella serovars in poultry: exploitation of innate immunity and microbial activity. Epidemiol. Infect. 133, 959-978.

Vanderplas, S., Dubois Dauphin, R., Beckers, Y., Thonart, P., and Thewis, A. (2010). Salmonella in chicken: Current and developing strategies to reduce contamination at farm level. J. Food Prot. 73. 774-785.

Volkova, V.V., Bailey, R.H. and Wills, R.W., (2009). Salmonella in broiler litter and properties of soil at farm location. PLoS ONE 4(7): e6403. doi:10.1371/journal.pone.0006403. 
Wales, A. D., Carrique-Mas, J. J., Rankin, M., Bell, B., Thind, B. B. and Davies, R. H. (2010), Review of the carriage of zoonotic bacteria by arthropods, with special reference to Salmonella in mites, flies and litter beetles. Zoonoses Public Health, 57, 299-314.

Wilkie, D.C., Van Kessel, A.G., Dumonnceaux, T. J. and Drew, M. D. (2006). The effect of hen egg antibodies on Clostridium perfringens colonization in the gastrointestinal tract of broiler chickens. Prevent. Vet. Med. 74, 279-292.

Withanage, G.S.K., Wigley, P., Kaiser, P., Mastroeni, P., Brooks, H., Powers, C., Beal, R., Barrow, P., Maskell, D., and McConnell, I. (2005). Cytokine and chemokine responses associated with clearance of a primary Salmonella enterica serovar Typhimurium infection in the chicken and in protective immunity to rechallenge. Infect. Immun. Aug, 5173-5182.

Woodward, M.J., Gettinby, G., Breslin, M.F., Corkish, J.D. and Houghton, S. (2002). The efficacy of Salenvac, a Salmonella enterica subsp. Enterica serovar Enteritidis ironrestricted bacterin vaccine, in laying chickens. Avian Pathol. 31, 383-392.

$\mathrm{x}-\mathrm{OVO}$ (Guildhay) Flockscreen ${ }^{\mathrm{TM}}$ Salmonella Typhimurium (St) antibody kit Instruction for use (v4). Inverkeithing, Scotland, UK.

Yegani, M. and Korver, D. R. (2010). Application of egg yolk antibodies as replacement for antibiotics in poultry. World Poult. Sci. J., 66, 27-37.

Zhang-Barber, L., Turner, A.K., and Barrow, P.A. (1999). Vaccination for the control of Salmonella in poultry. Vacc. 17, 2538-2545. 


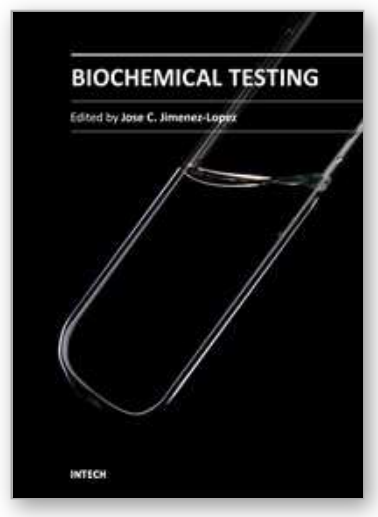

\author{
Biochemical Testing \\ Edited by Dr. Jose C. Jimenez-Lopez
}

ISBN 978-953-51-0249-6

Hard cover, 216 pages

Publisher InTech

Published online 07, March, 2012

Published in print edition March, 2012

Biochemical testing necessitates the determination of different parameters, and the identification of the main biological chemical compounds, by using molecular and biochemical tools. The purpose of this book is to introduce a variety of methods and tools to isolate and identify unknown bacteria through biochemical and molecular differences, based on characteristic gene sequences. Furthermore, molecular tools involving DNA sequencing, and biochemical tools based in enzymatic reactions and proteins reactivity, will serve to identify genetically modified organisms in agriculture, as well as for food preservation and healthcare, and improvement through natural products utilization, vaccination and prophylactic treatments, and drugs testing in medical trials.

\title{
How to reference
}

In order to correctly reference this scholarly work, feel free to copy and paste the following:

Anthony Pavic, Peter J. Groves and Julian M. Cox (2012). Control of Salmonella in Poultry Through Vaccination and Prophylactic Antibody Treatment, Biochemical Testing, Dr. Jose C. Jimenez-Lopez (Ed.), ISBN: 978-953-51-0249-6, InTech, Available from: http://www.intechopen.com/books/biochemicaltesting/control-of-poultry-salmonella-through-vaccination-and-prophalytic-antibody-treatment-

\section{INTECH}

open science | open minds

\section{InTech Europe}

University Campus STeP Ri

Slavka Krautzeka 83/A

51000 Rijeka, Croatia

Phone: +385 (51) 770447

Fax: +385 (51) 686166

www.intechopen.com

\section{InTech China}

Unit 405, Office Block, Hotel Equatorial Shanghai

No.65, Yan An Road (West), Shanghai, 200040, China

中国上海市延安西路65号上海国际贵都大饭店办公楼405单元

Phone: +86-21-62489820

Fax: +86-21-62489821 
(C) 2012 The Author(s). Licensee IntechOpen. This is an open access article distributed under the terms of the Creative Commons Attribution 3.0 License, which permits unrestricted use, distribution, and reproduction in any medium, provided the original work is properly cited. 